\title{
Extra Graphs
}


PCA Shiny - Graphs 


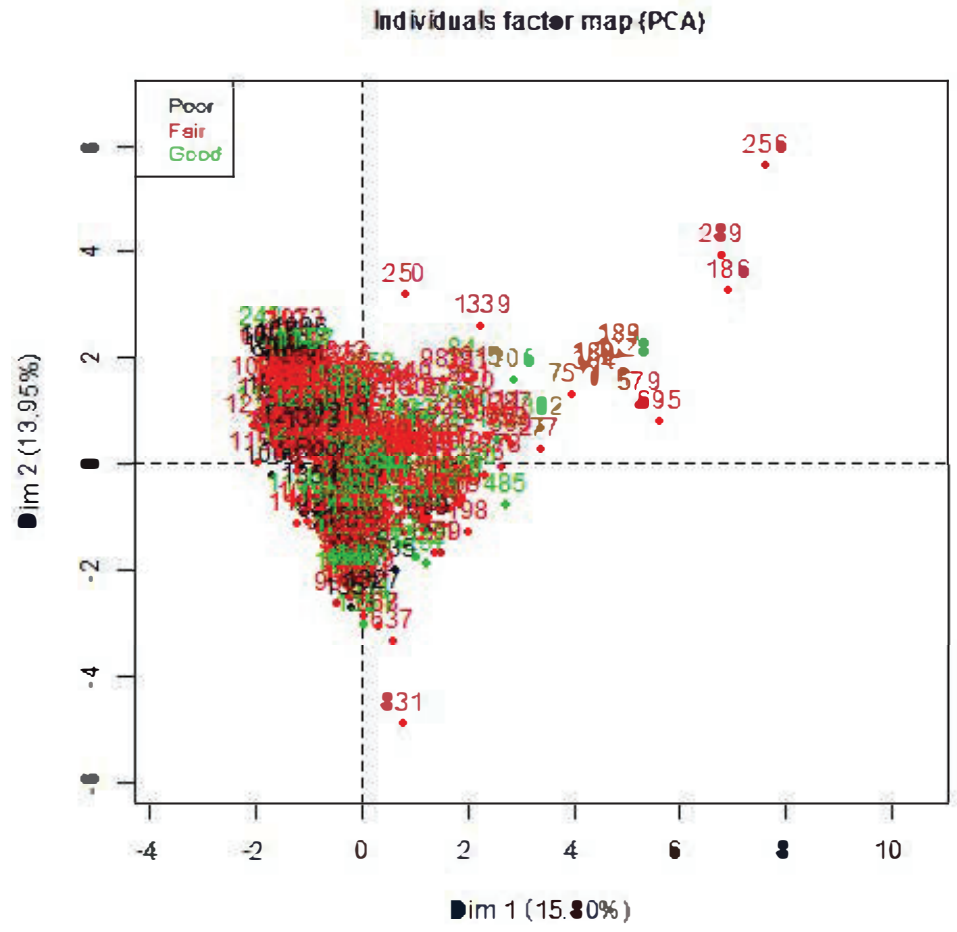

FUNCTION: PCASHINY, 2015 Dataset, Independent Input Variables: EA, L

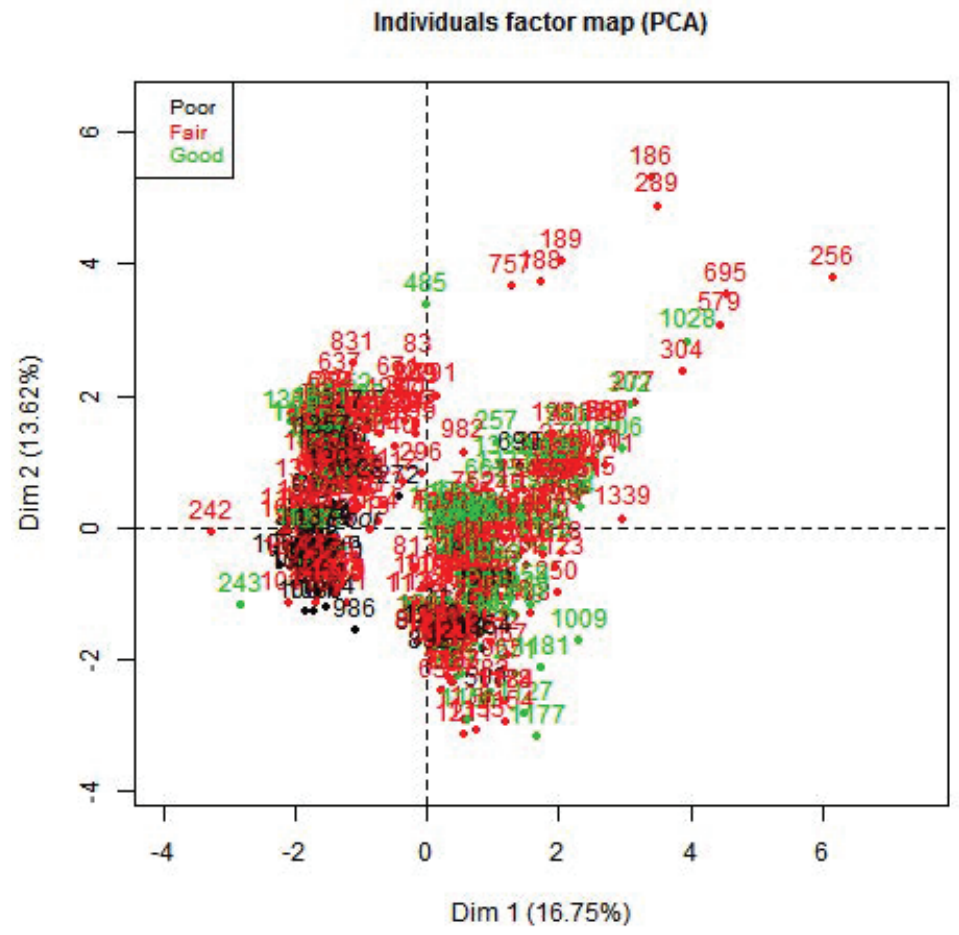


FUNCTION: PCASHINY, 2015 Dataset, Independent Input Variables: AE, EA, CZ

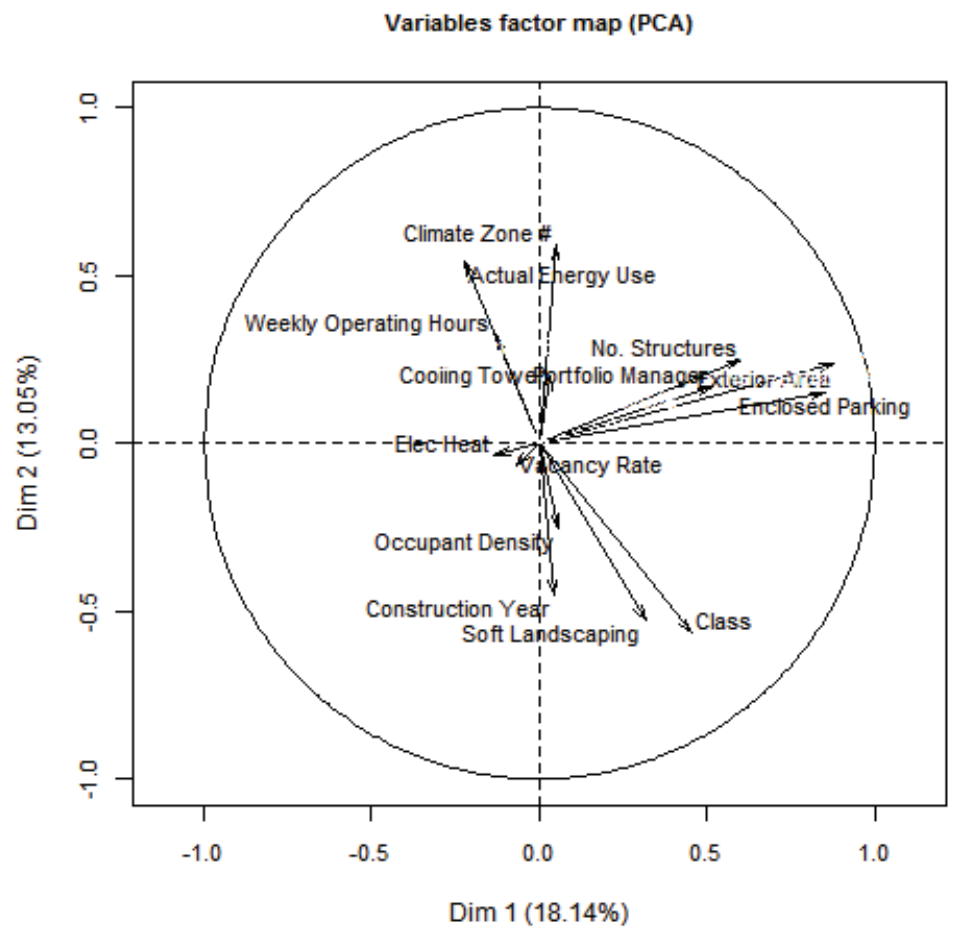

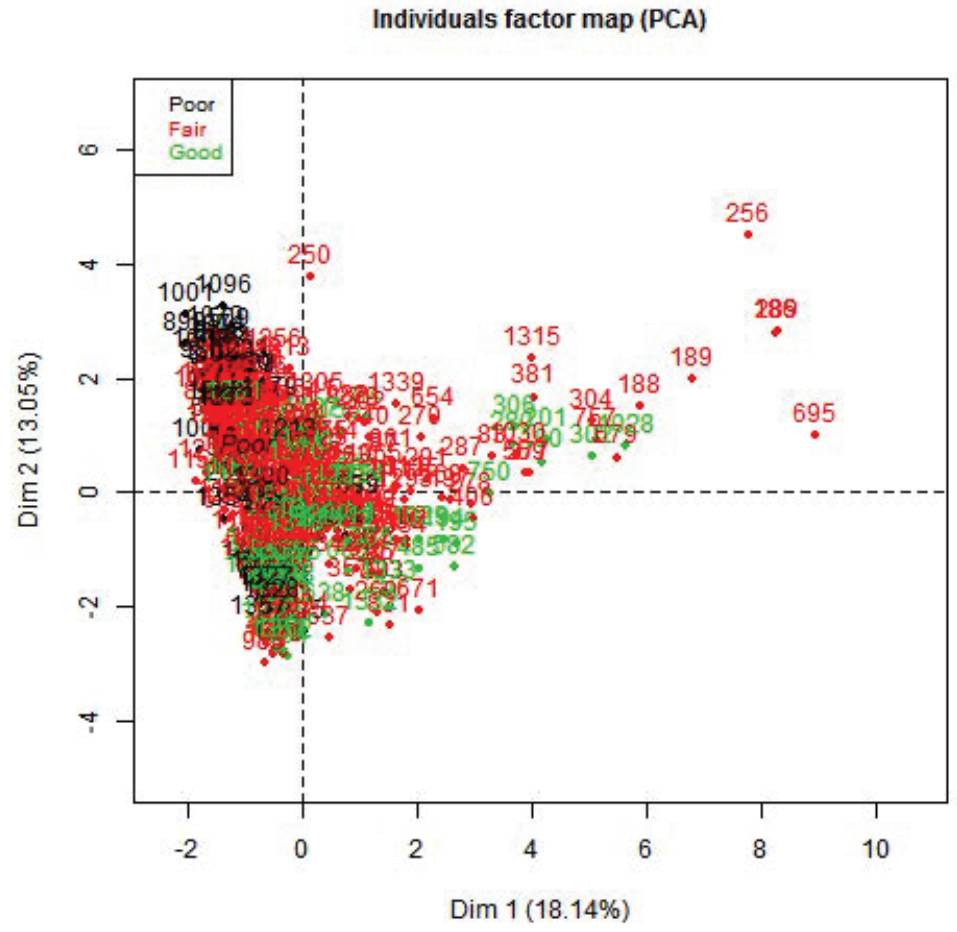


FUNCTION: PCASHINY, 2015 Dataset, Independent Input Variables: AE, EA, L_L
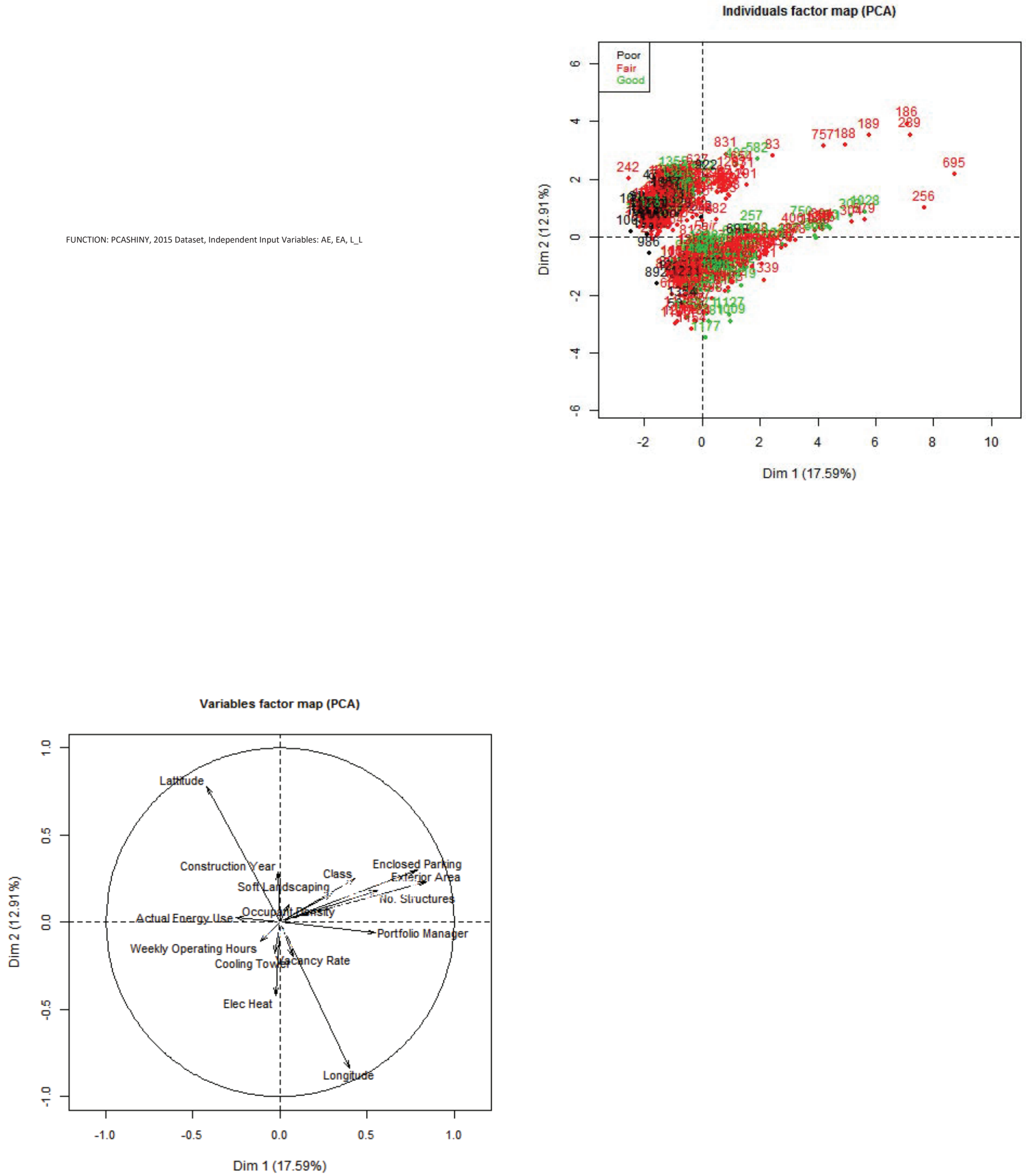
FUNCTION: PCASHINY, 2015 Dataset, Independent Input Variables: AE, EA+EP, CZ

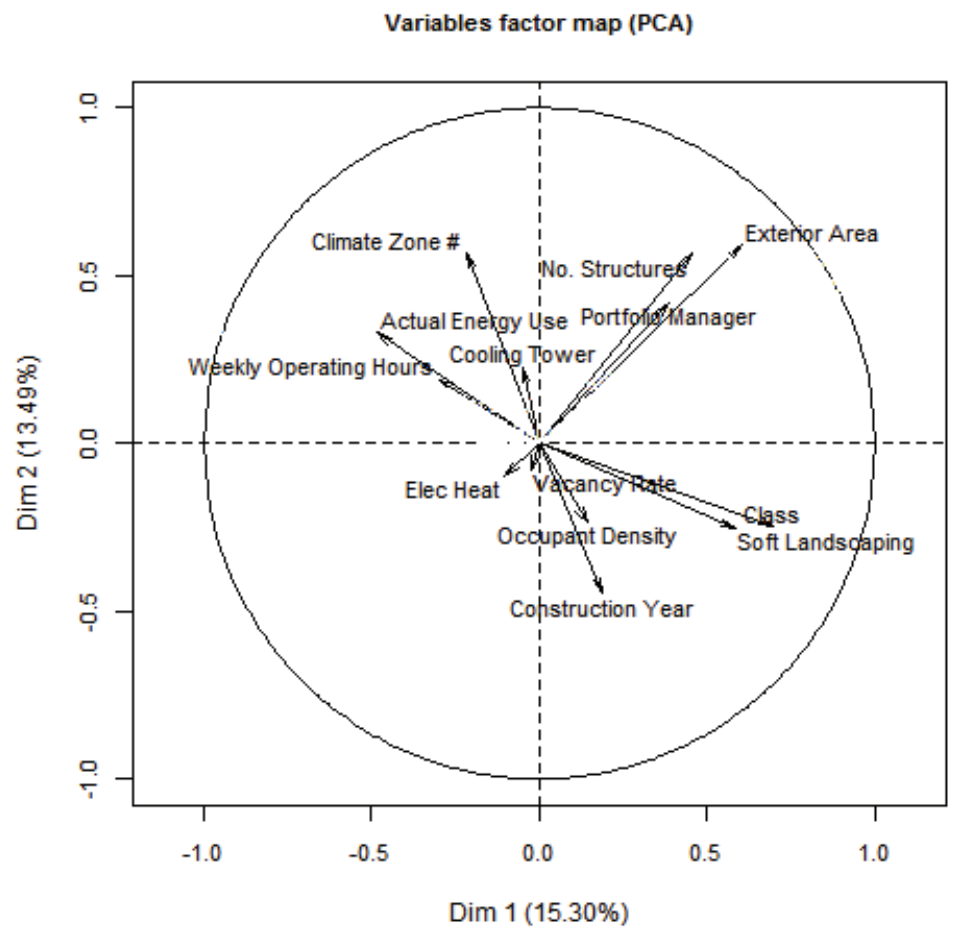

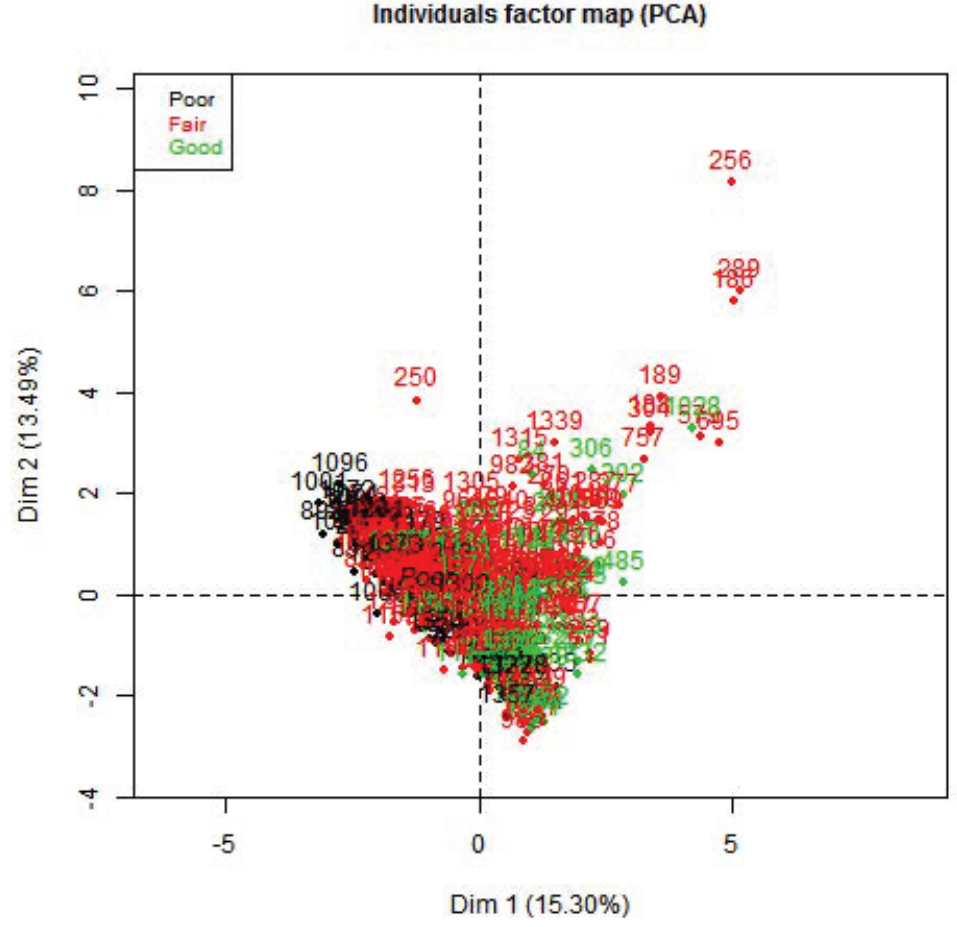



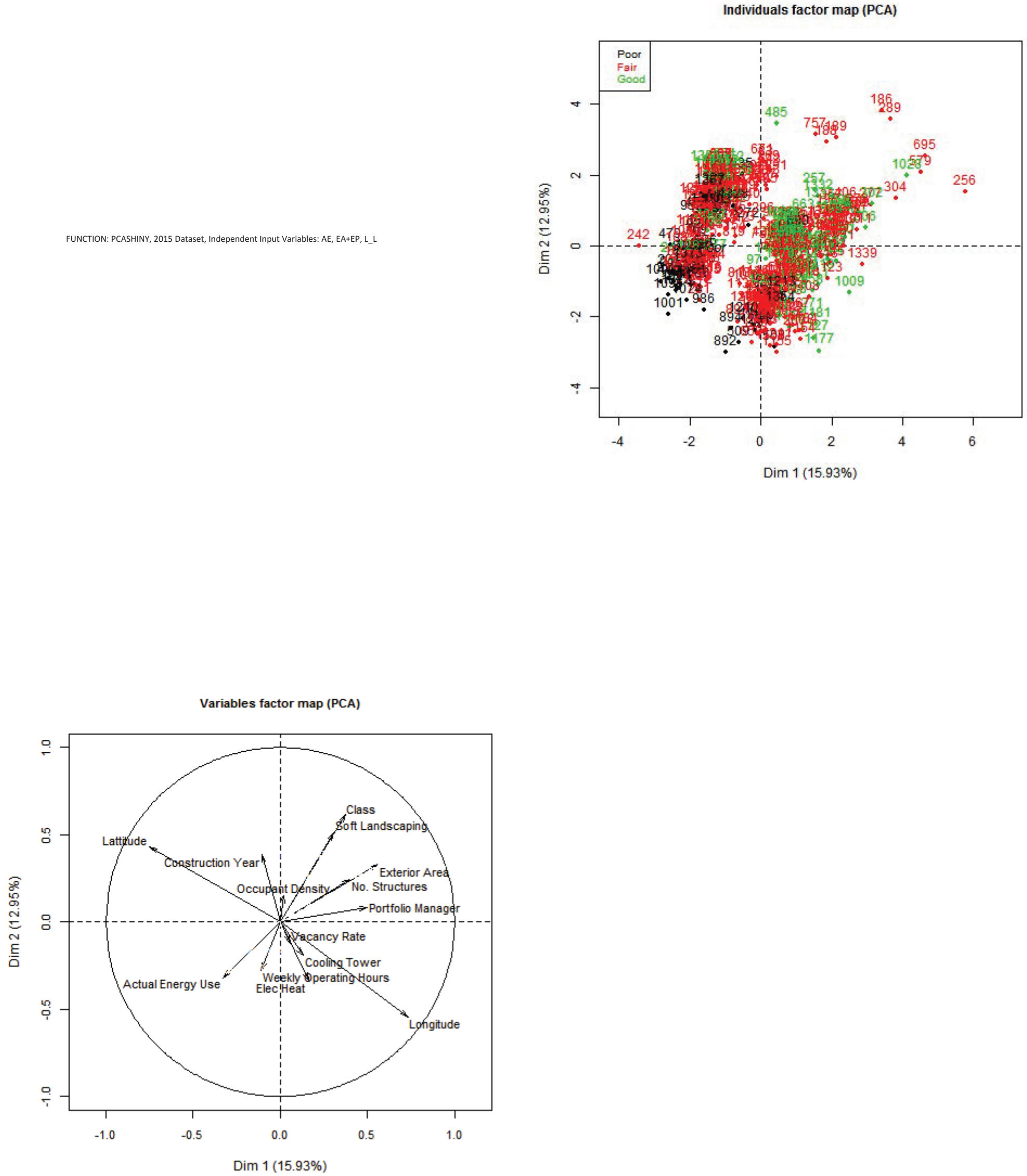
FUNCTION: PCASHINY, 2015 Dataset, Independent Input Variables: AE, GFA, CZ

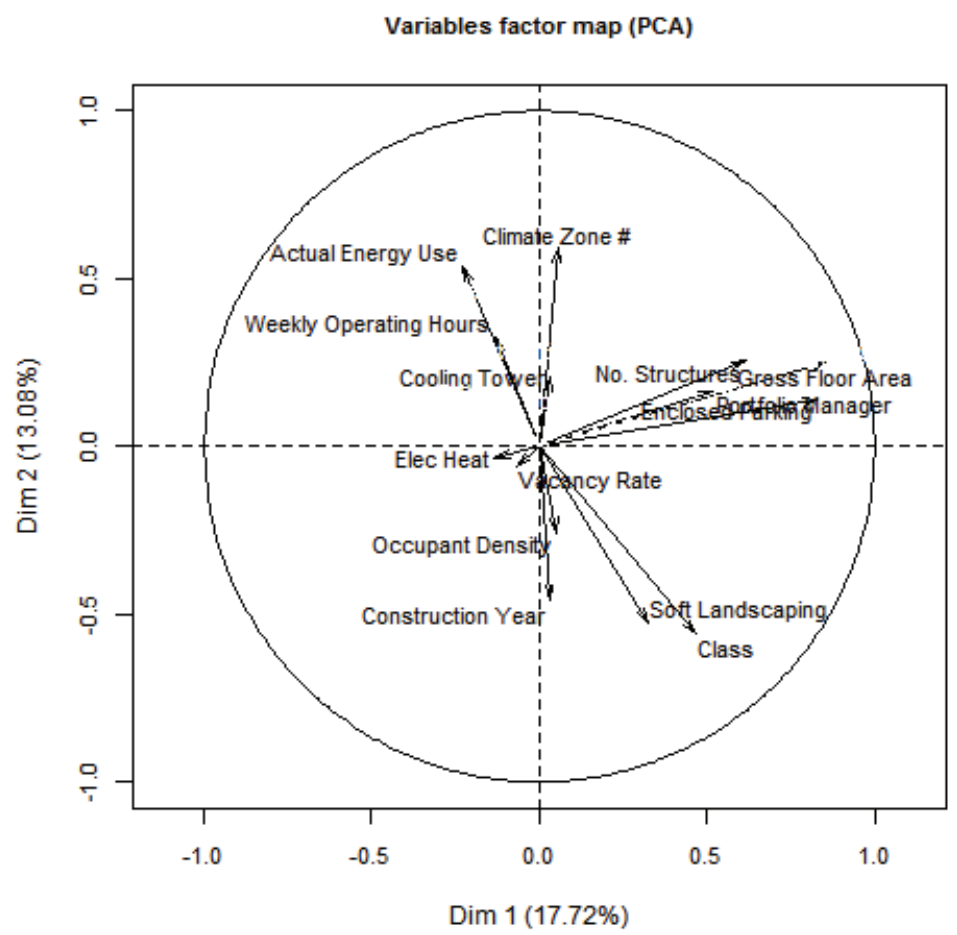

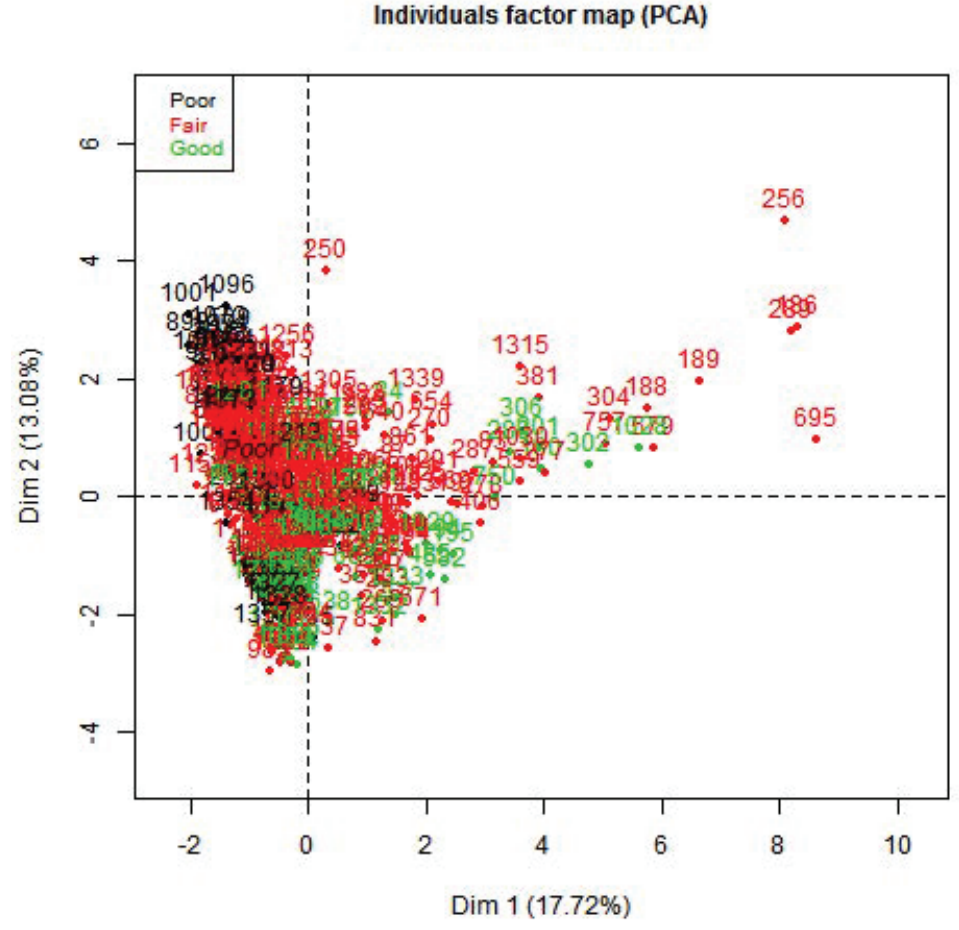


FUNCTION: PCASHINY, 2015 Dataset, Independent Input Variables: AE, GFA, L_L
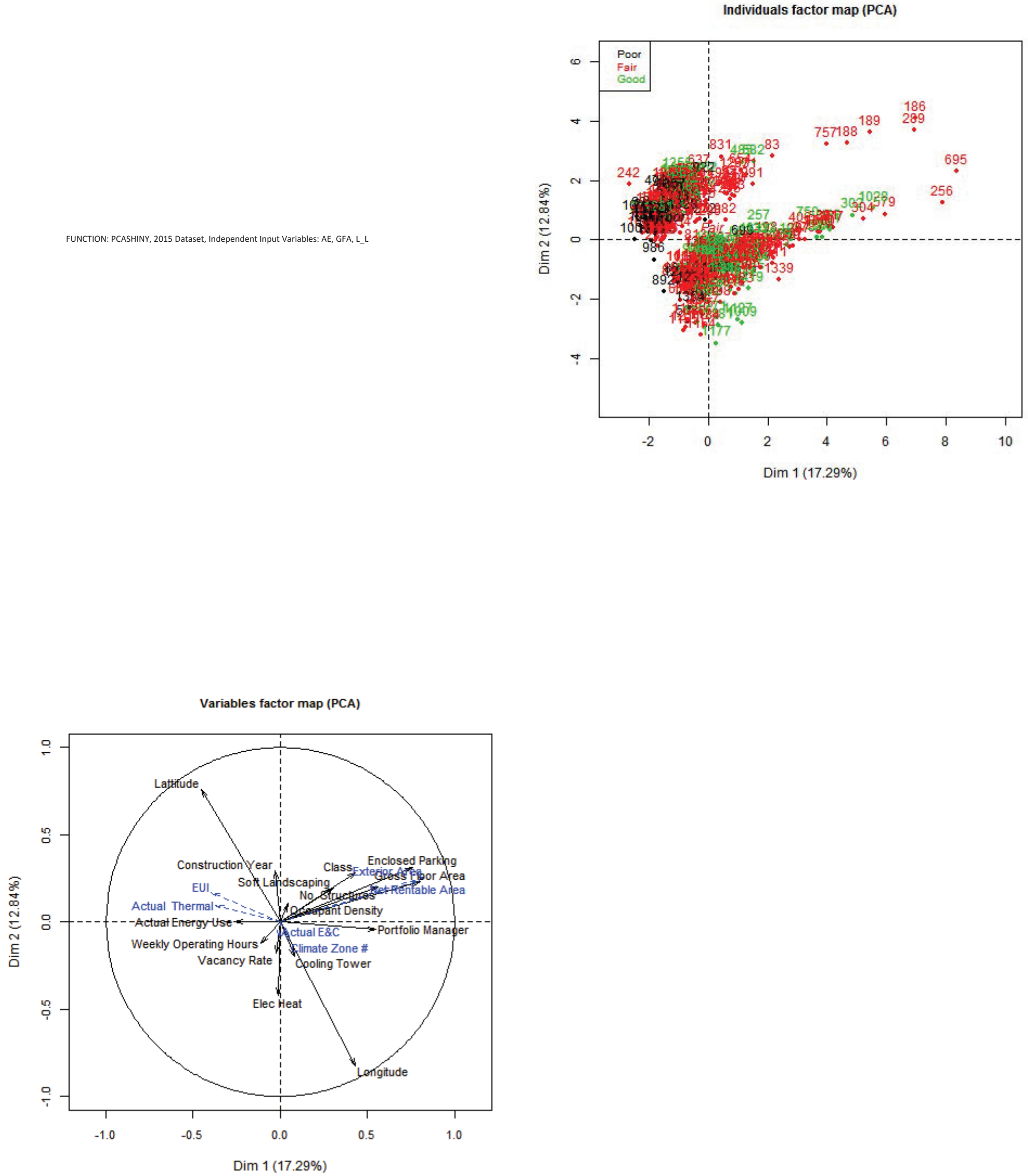
FUNCTION: PCASHINY, 2015 Dataset, Independent Input Variables: AE, GFA+EP, CZ
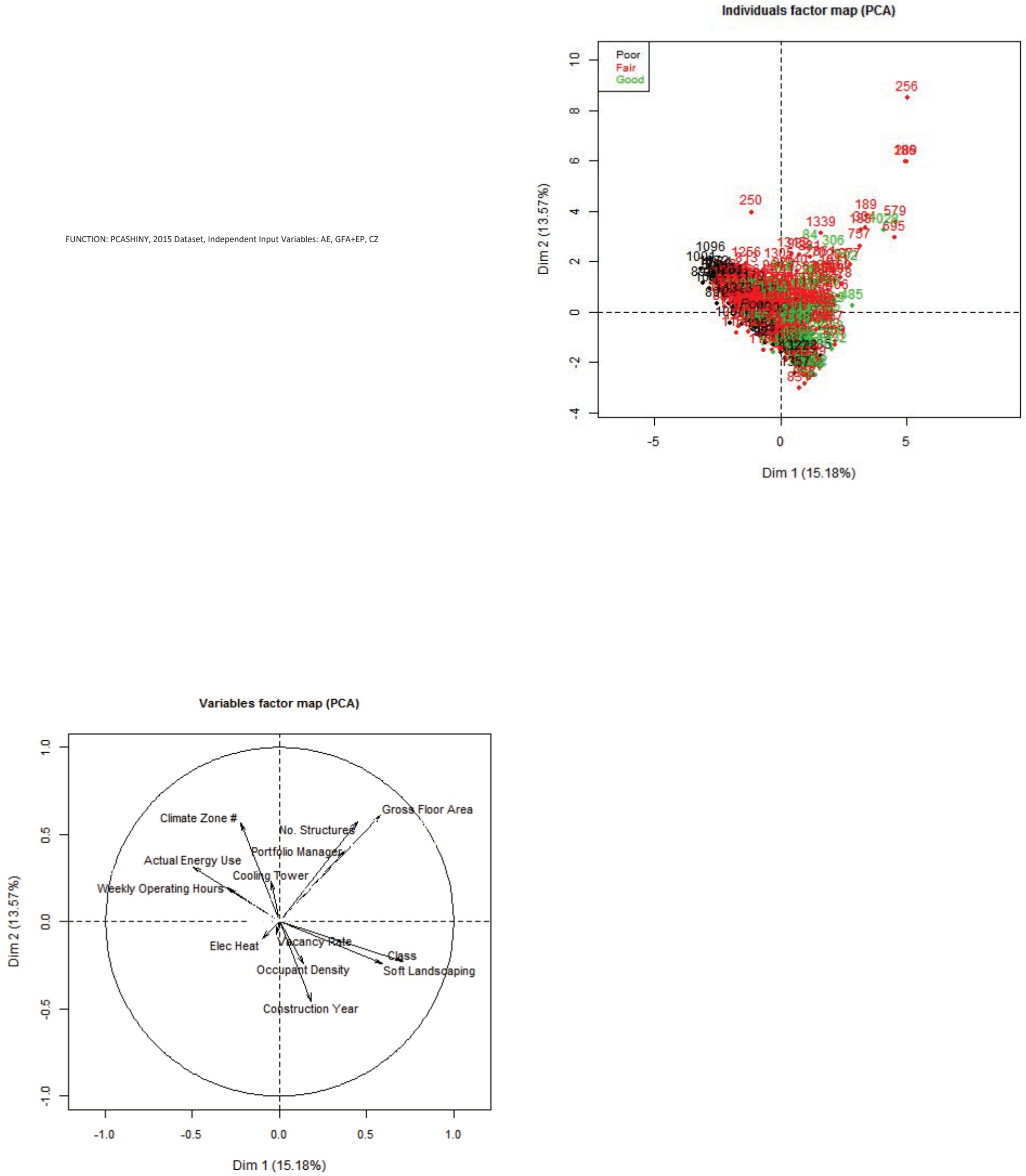

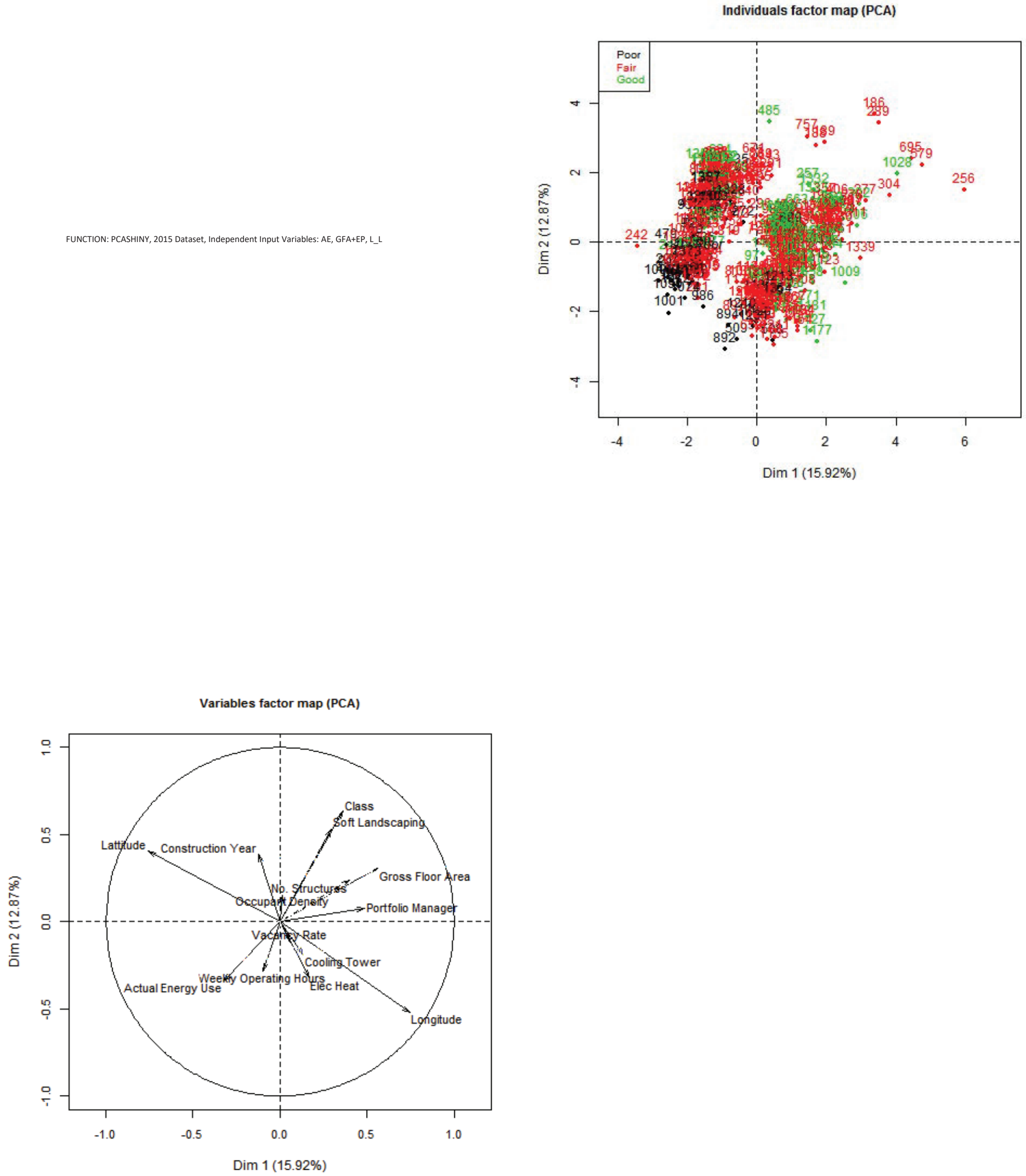
FUNCTION: PCASHINY, 2015 Dataset, Independent Input Variables: AE, NRA, CZ
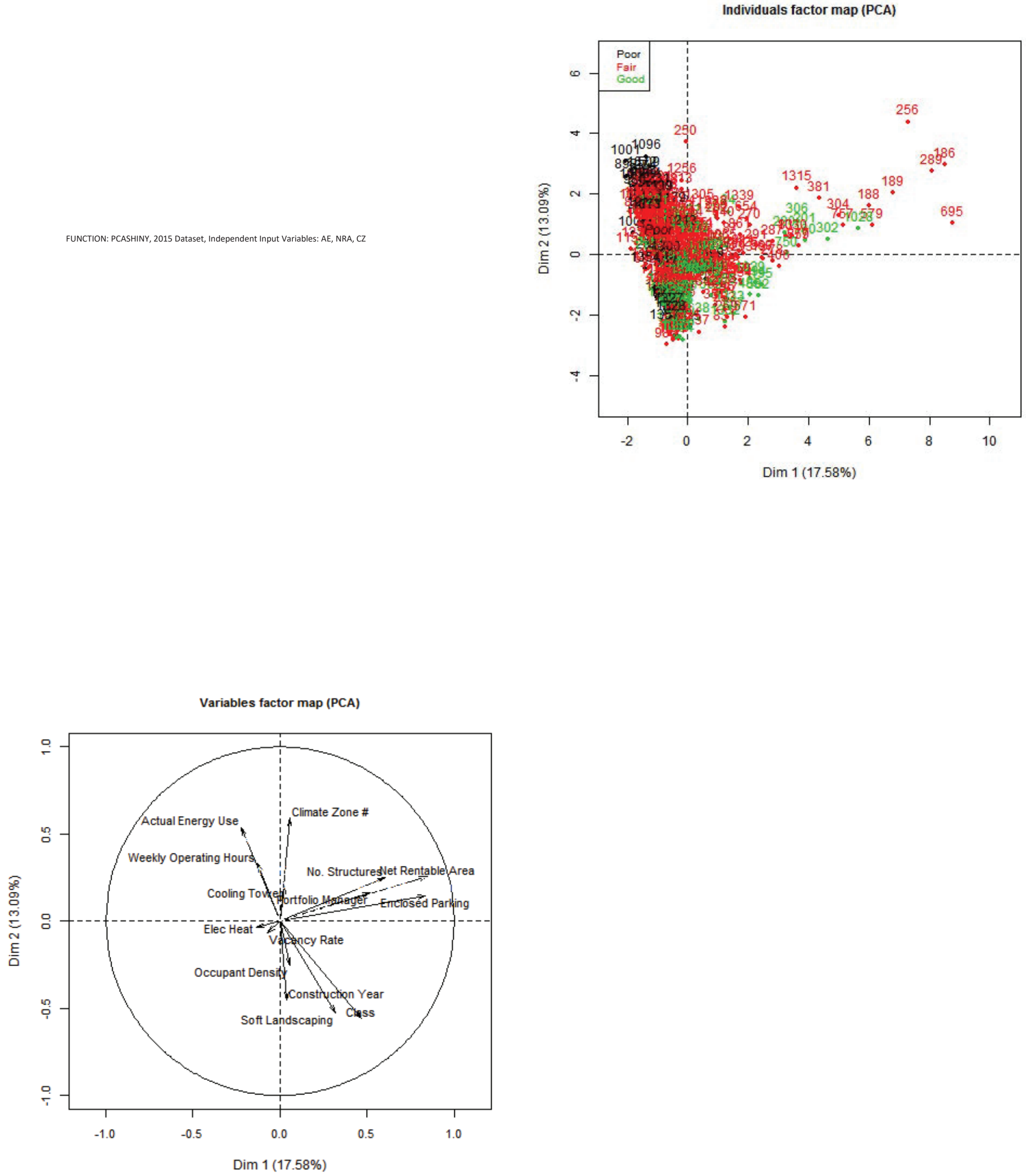
FUNCTION: PCASHINY, 2015 Dataset, Independent Input Variables: AE, NRA, L_L
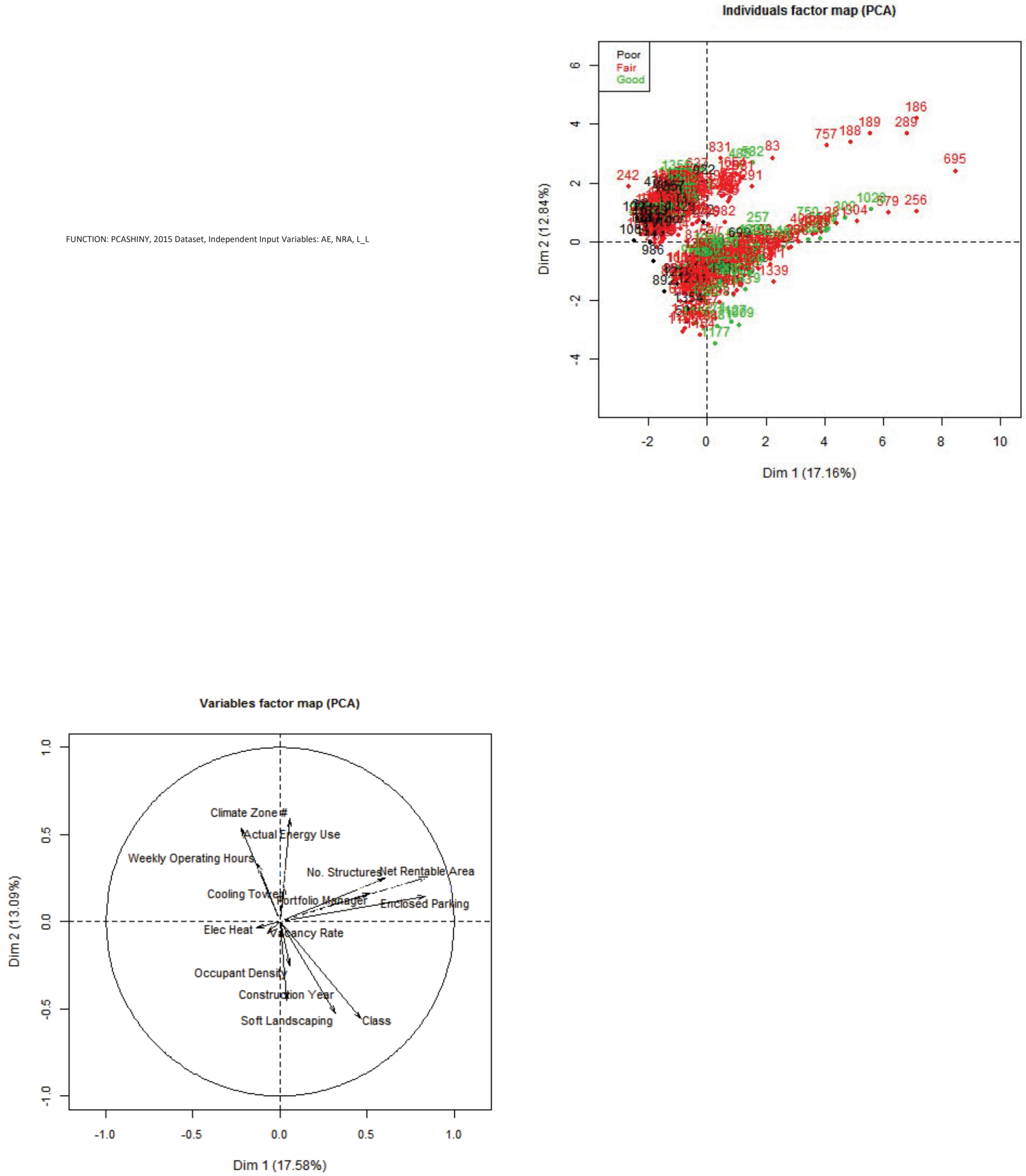
FUNCTION: PCASHINY, 2015 Dataset, Independent Input Variables: AE, NRA+EP, CZ
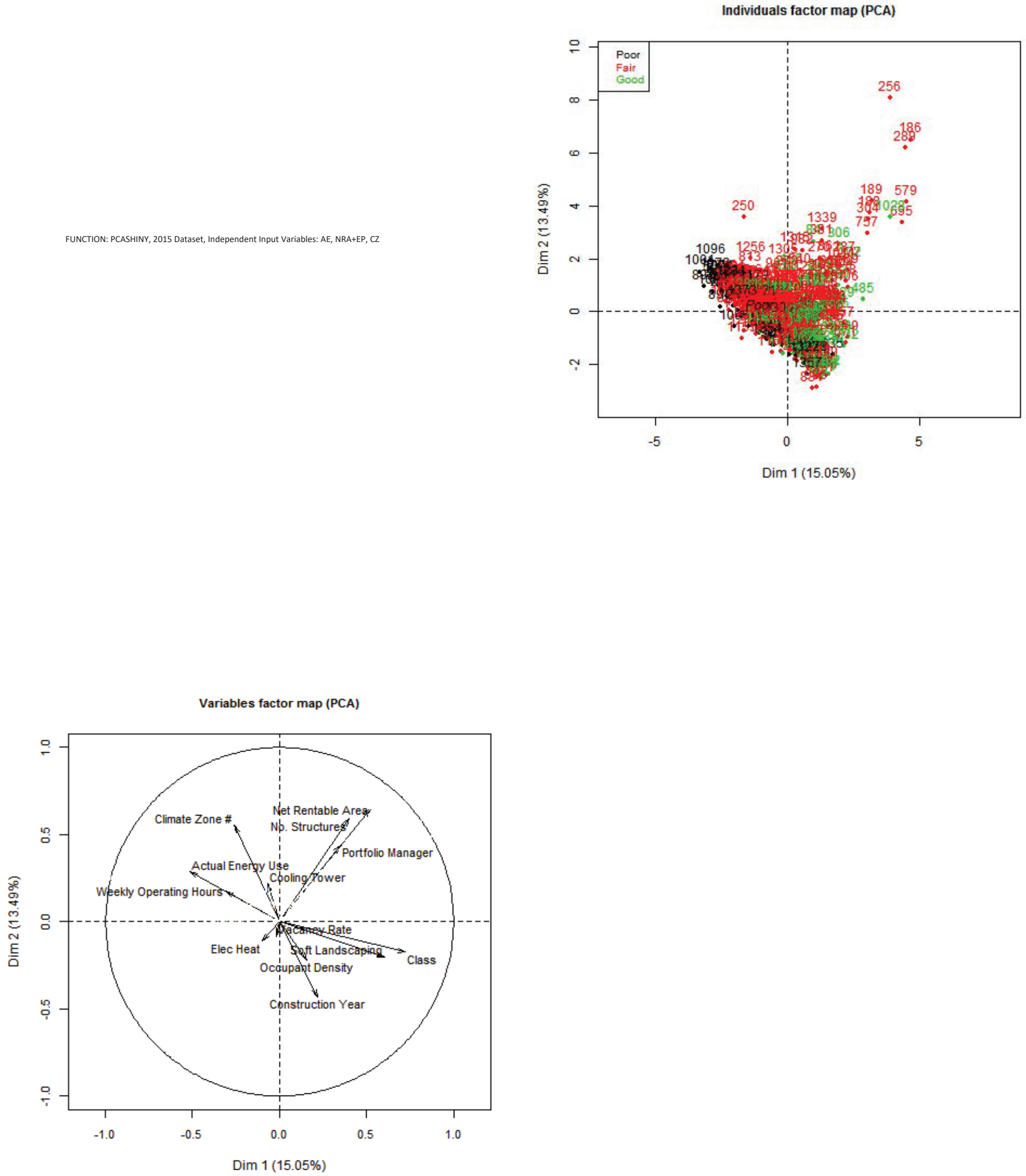

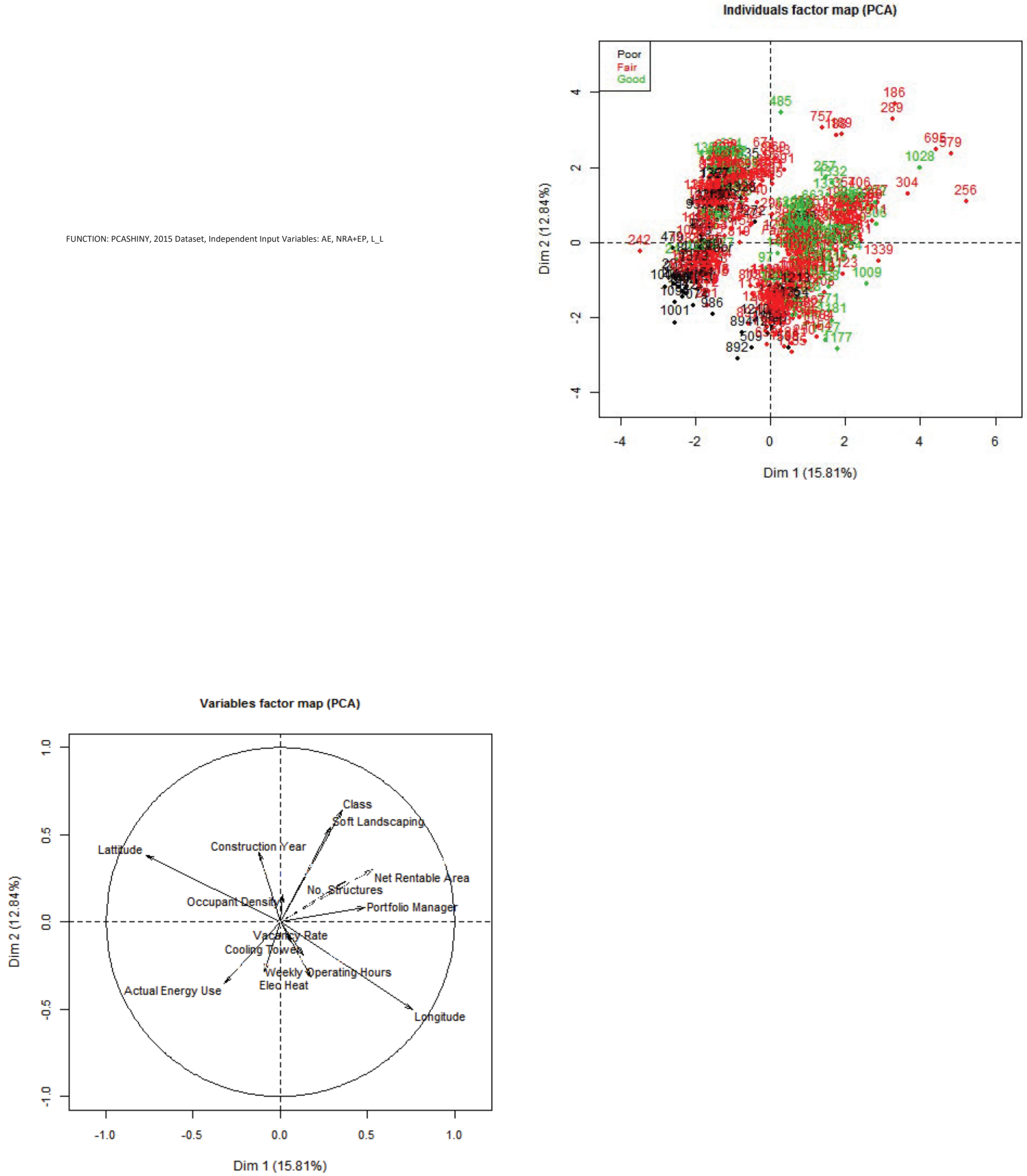
FUNCTION: PCASHINY, 2015 Dataset, Independent Input Variables: EA, CZ

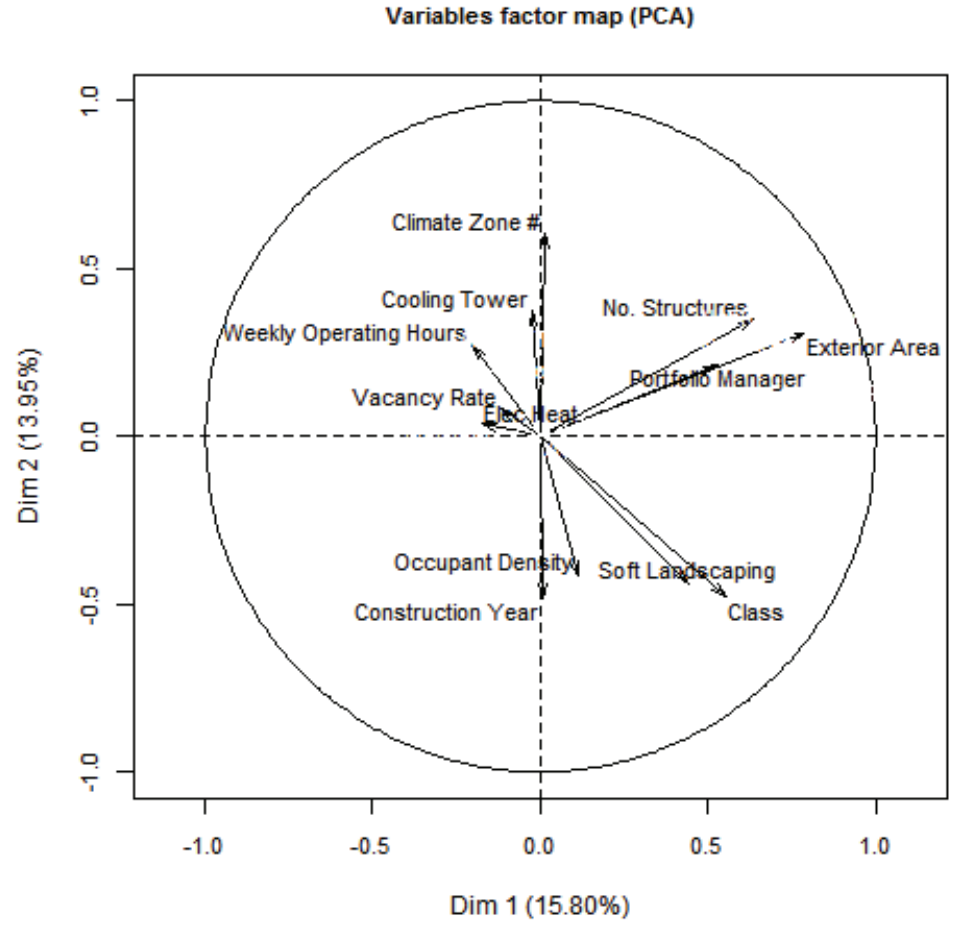

FUNCTION: PCASHINY, 2015 Dataset, Independent Input Variables: EA, L_L

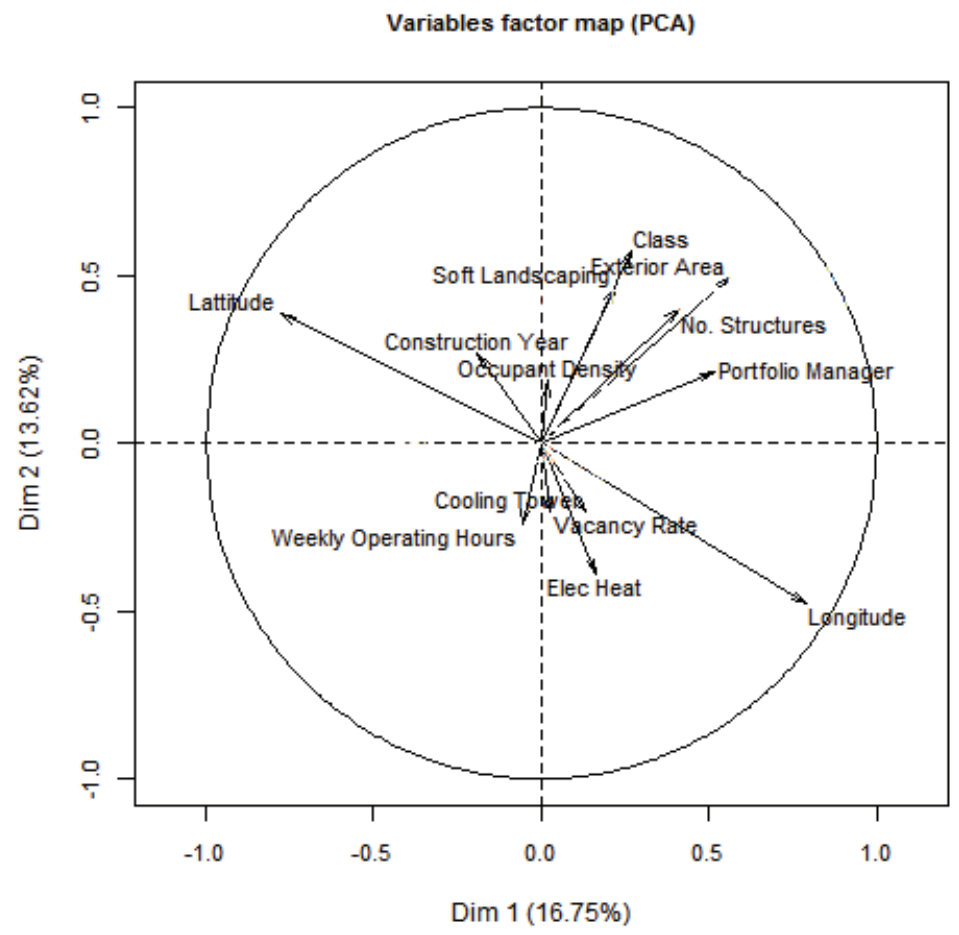


FUNCTION: PCASHINY, 2015 Dataset, Independent Input Variables: EUI, EA, CZ

Individuals factor map (PCA)

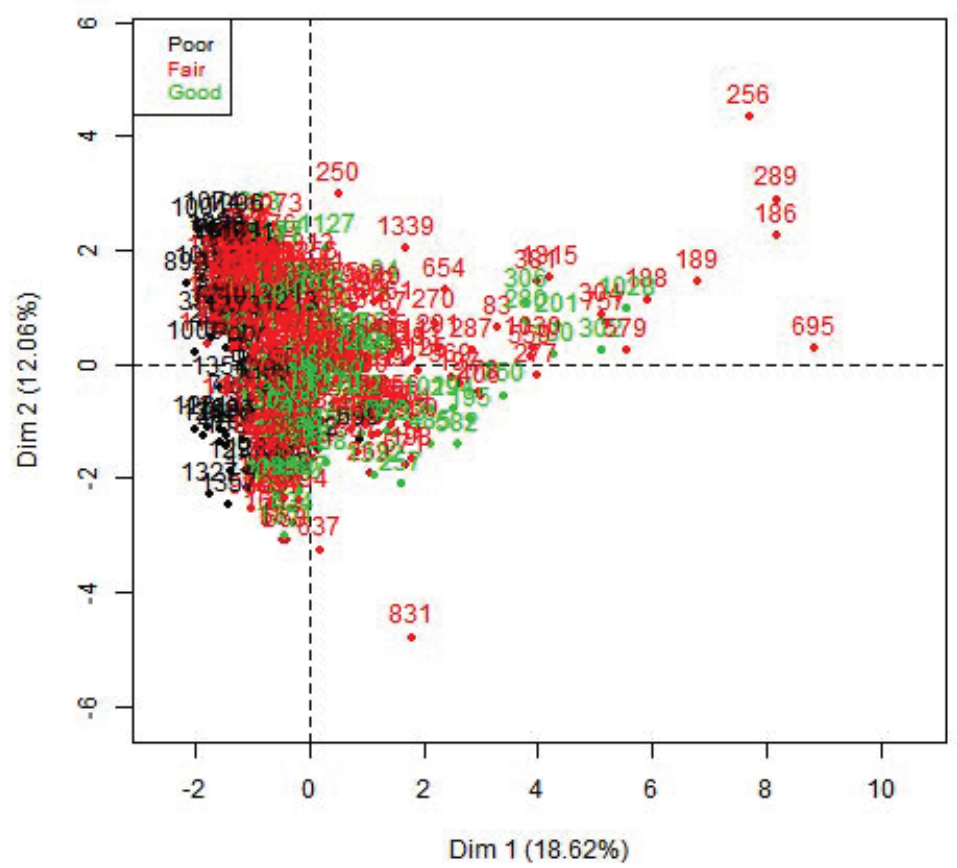

Variables factor map (PCA)

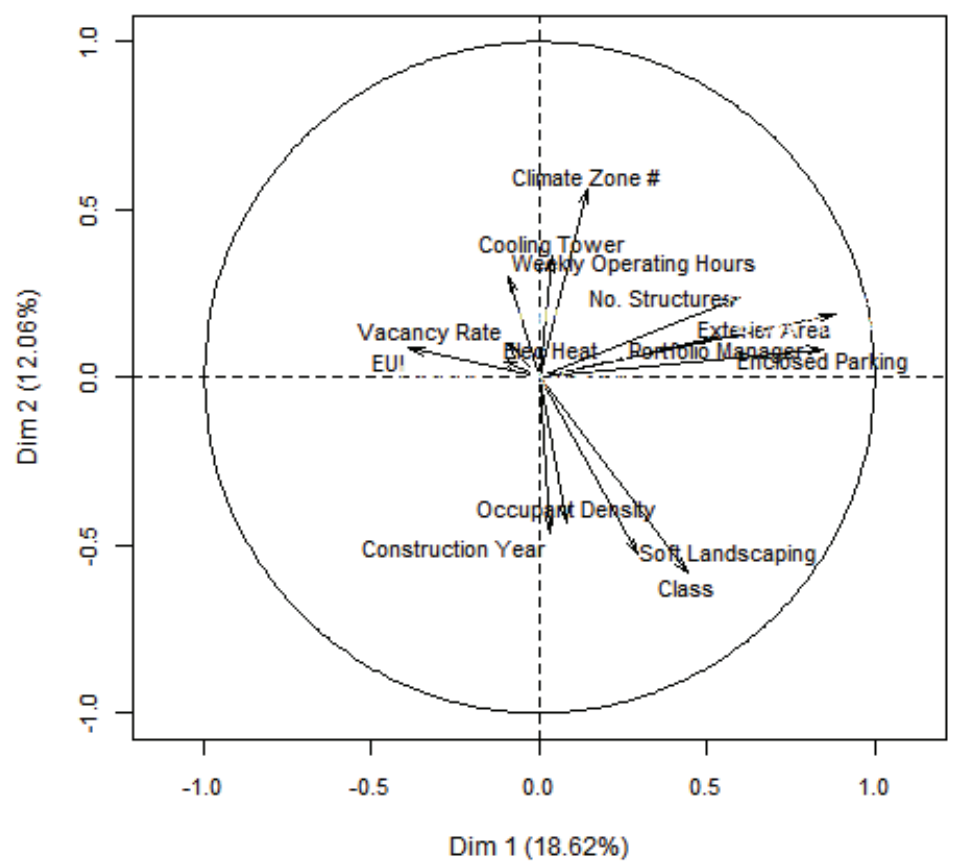


FUNCTION: PCASHINY, 2015 Dataset, Independent Input Variables: EUI, EA, L_L

Individuals factor map (PCA)

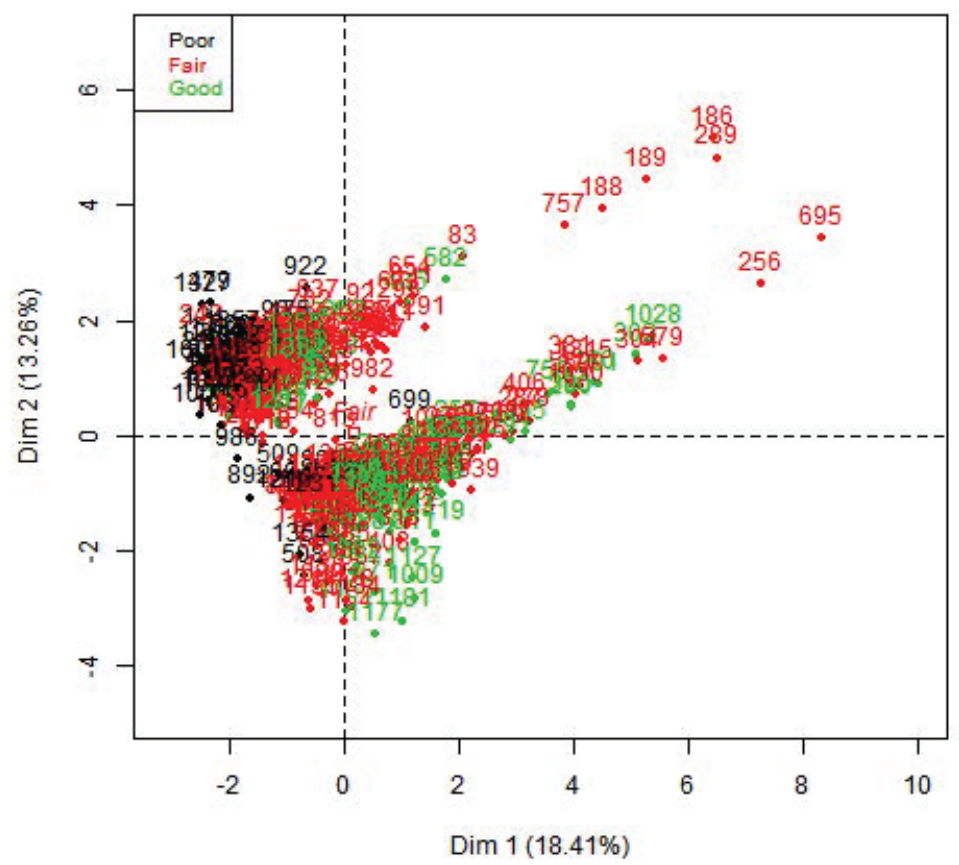

Variables factor map (PCA)

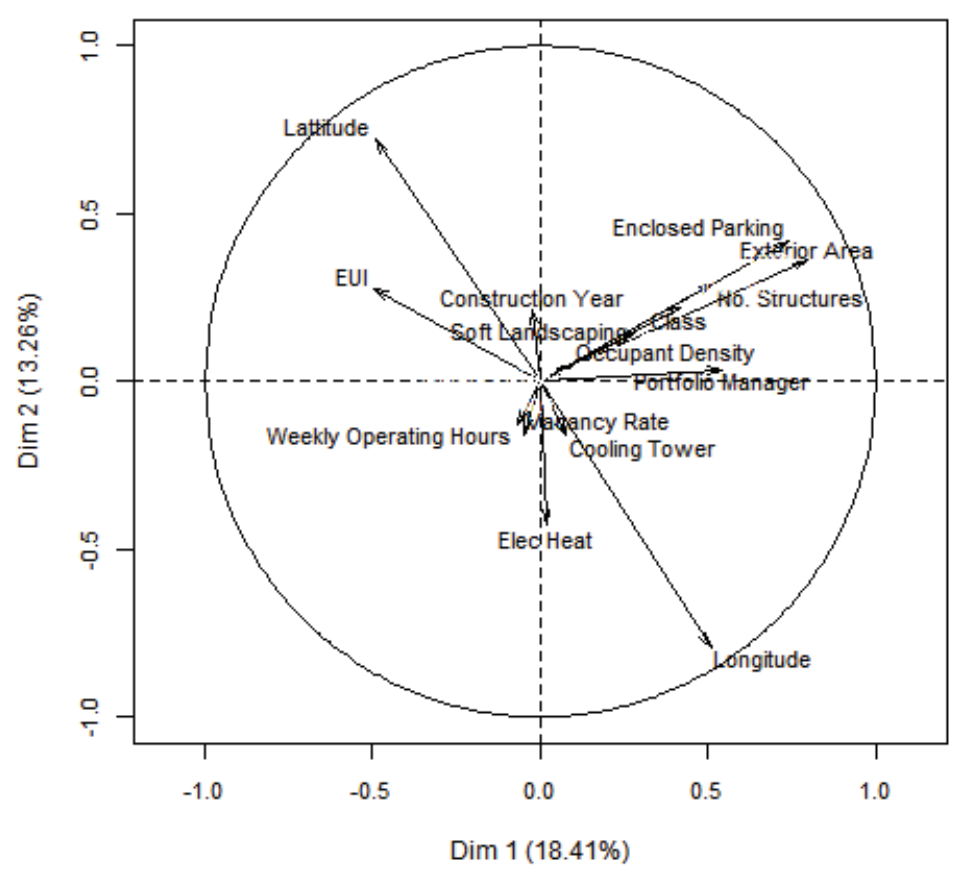


FUNCTION: PCASHINY, 2015 Dataset, Independent Input Variables: EUI, EA+EP, CZ

Individuals factor map (PCA)

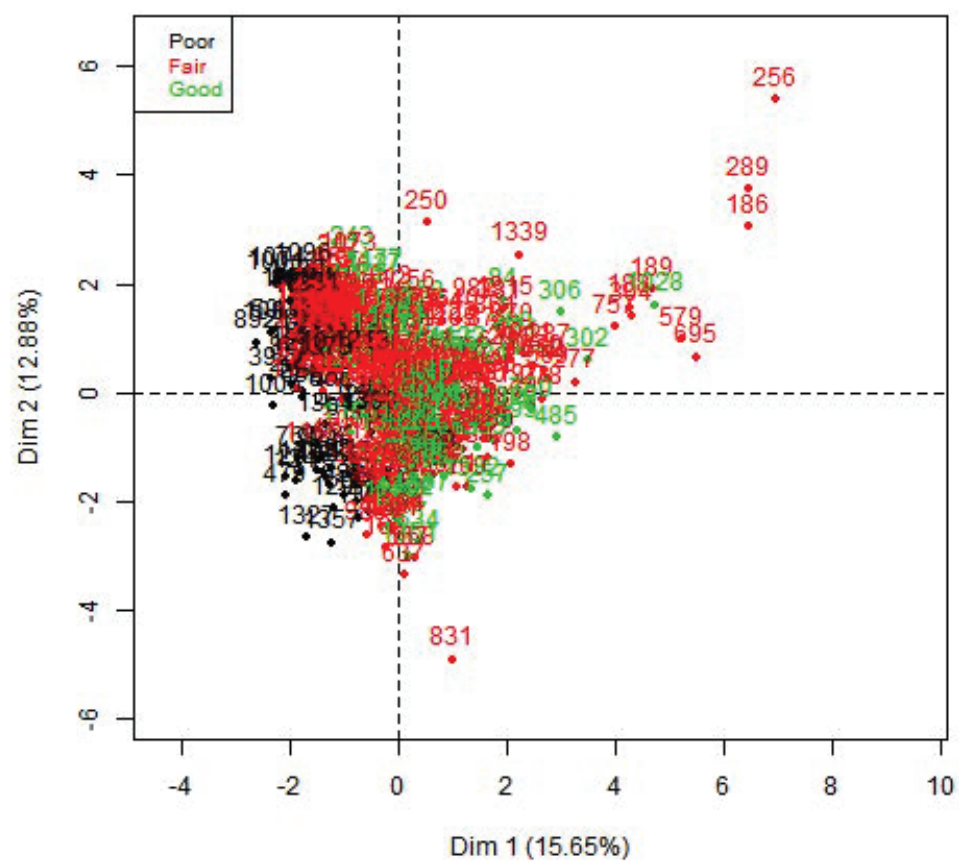

Variables factor map (PCA)

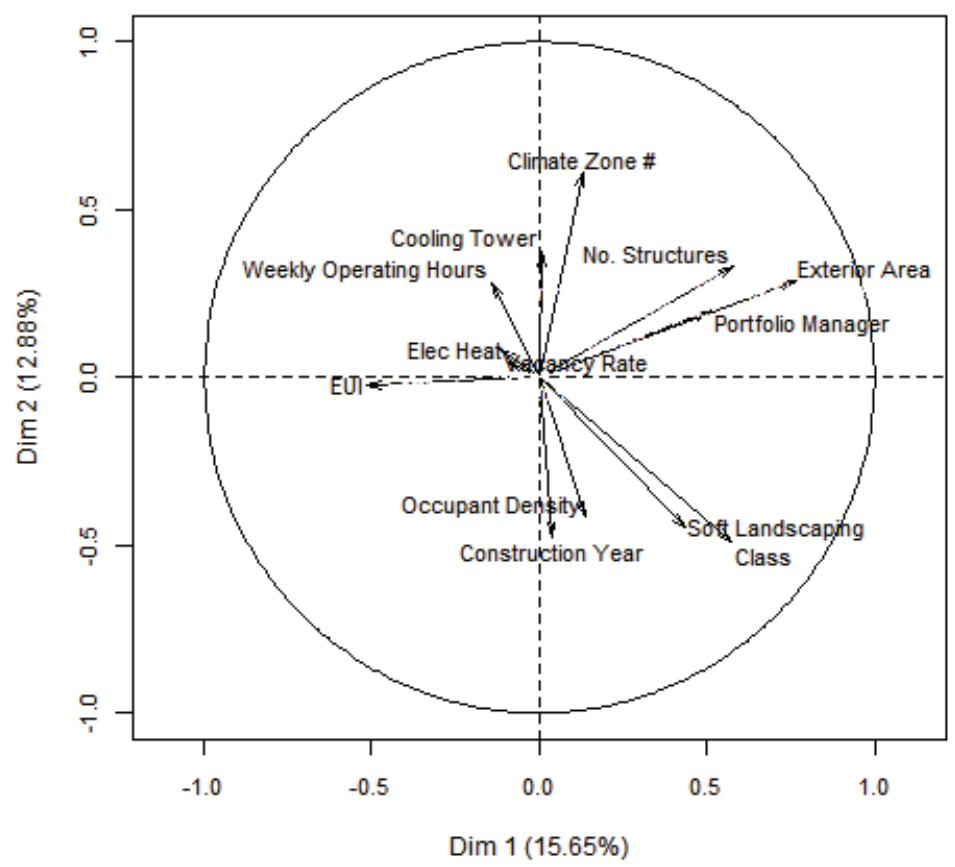


FUNCTION: PCASHINY, 2015 Dataset, Independent Input Variables: EUI, EA+EP, L_L

Individuals factor map (PCA)

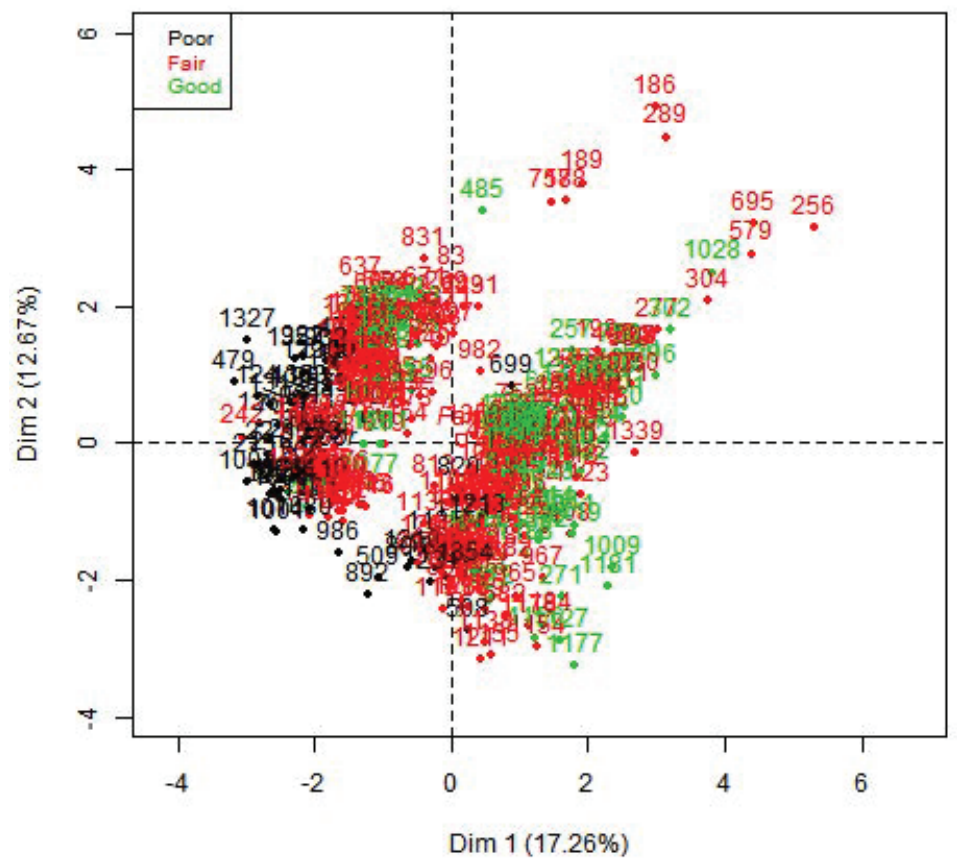

Variables factor map (PCA)

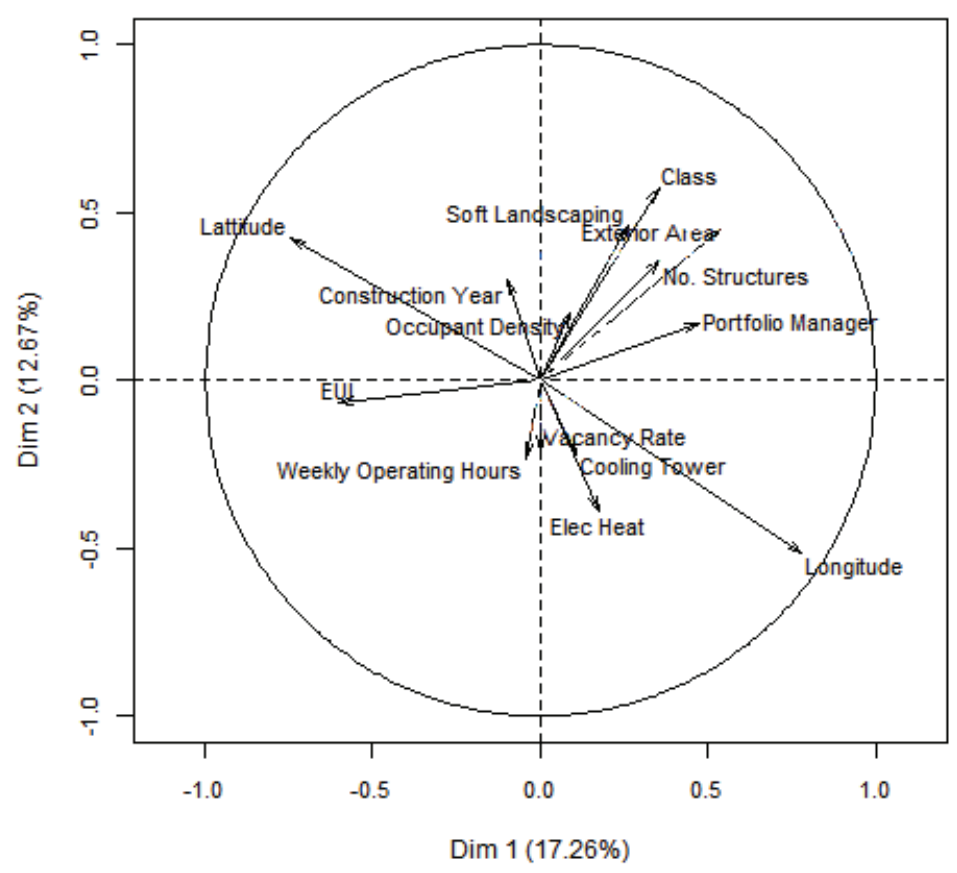


FUNCTION: PCASHINY, 2015 Dataset, Independent Input Variables: EUI, GFA, CZ

Individuals factor map (PCA)

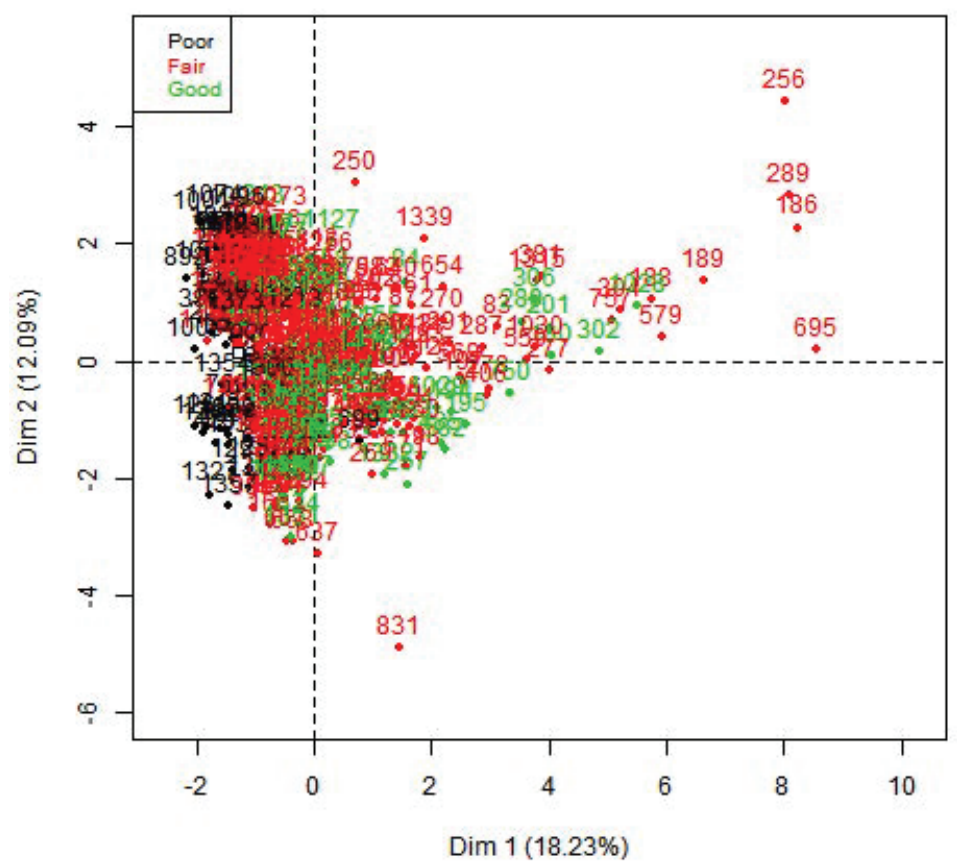

Variables factor map (PCA)

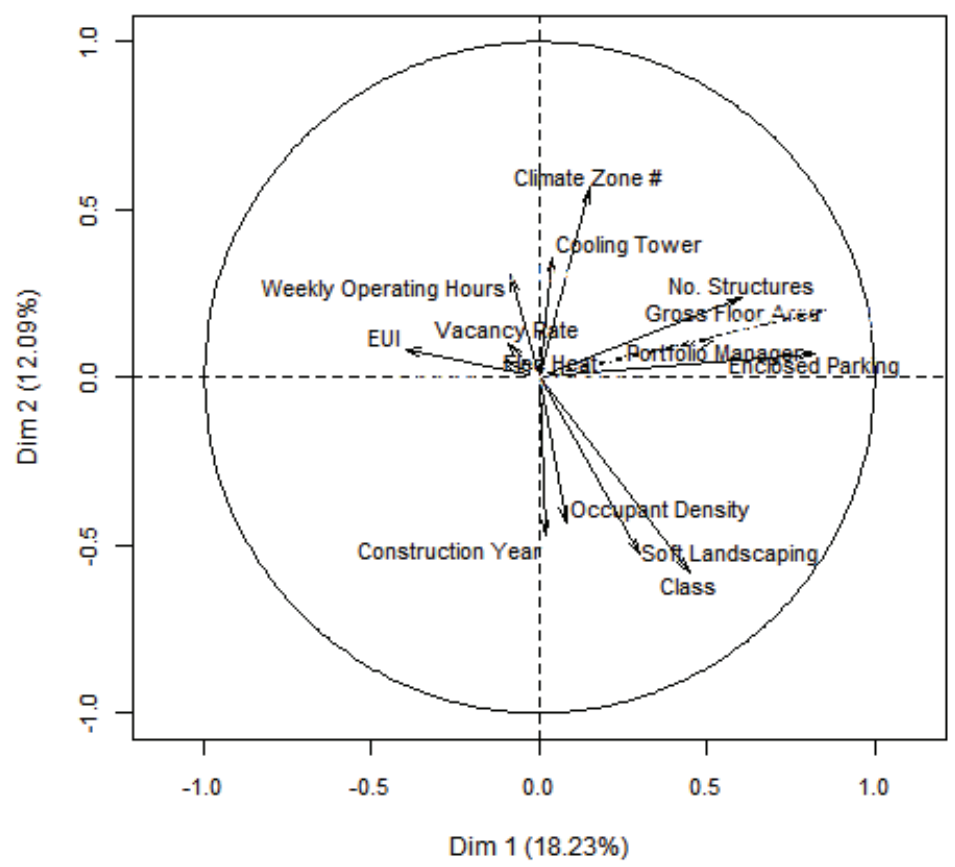


FUNCTION: PCASHINY, 2015 Dataset, Independent Input Variables: EUI, GFA, L_L

Individuals factor map (PCA)

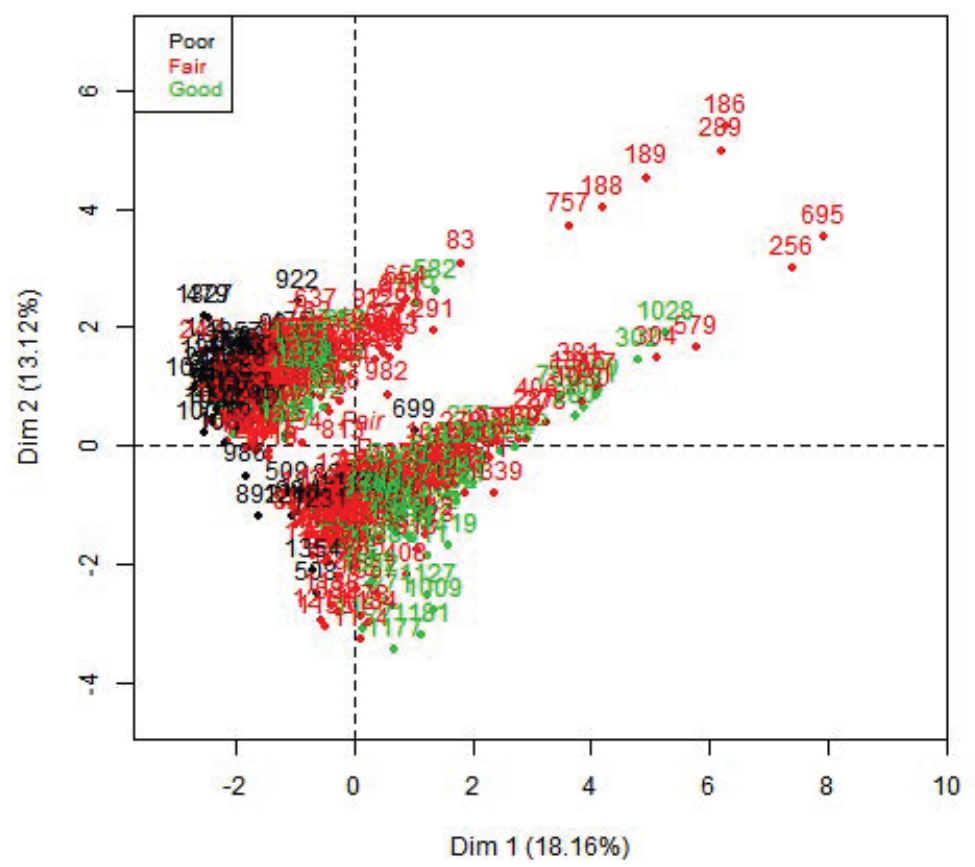

Variables factor map (PCA)

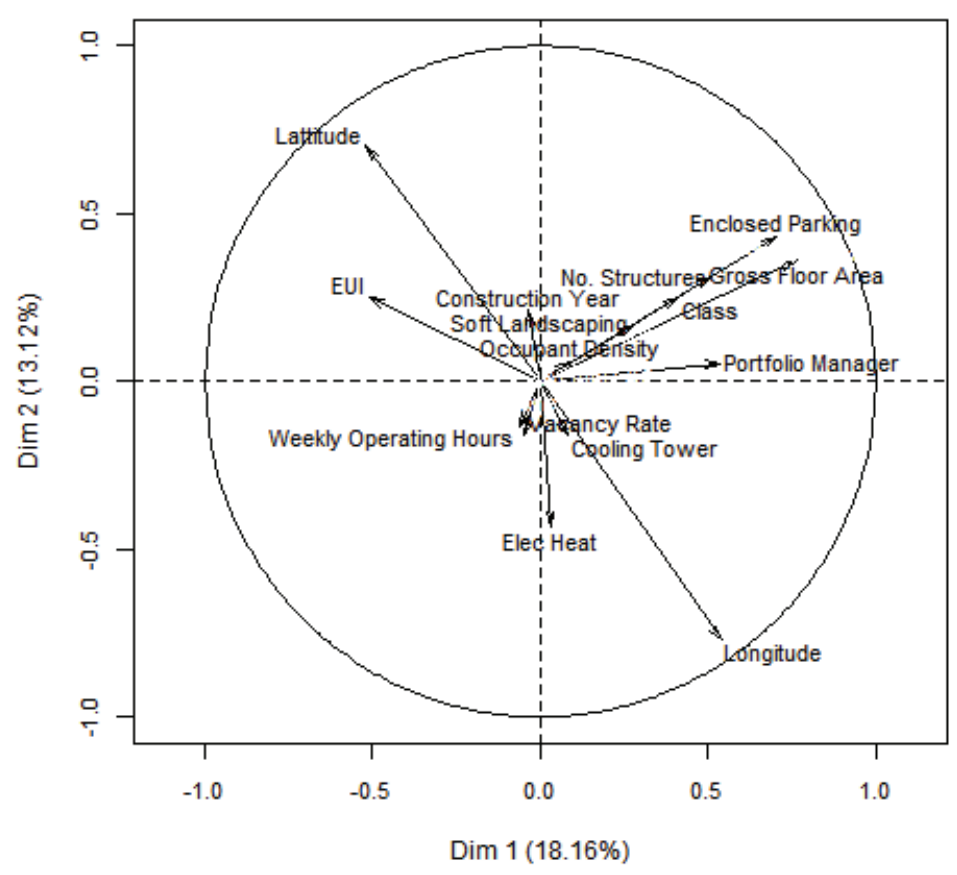


FUNCTION: PCASHINY, 2015 Dataset, Independent Input Variables: EUI, GFA+EP, CZ

Individuals factor map (PCA)

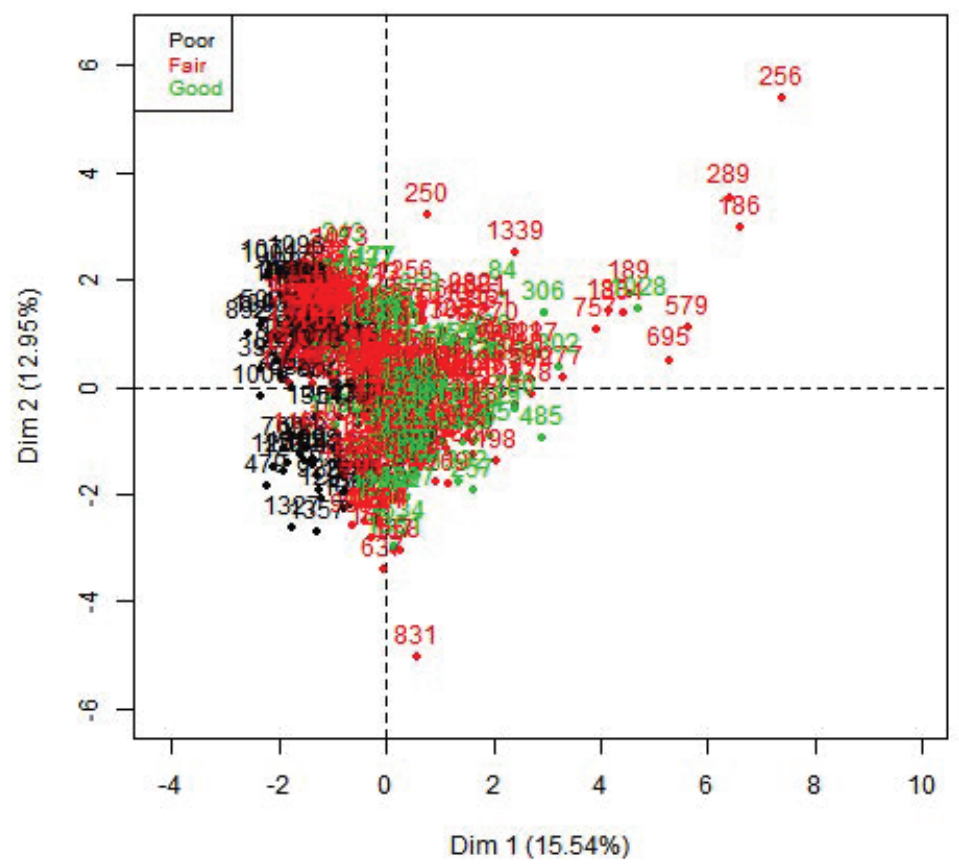

Variables factor map (PCA)

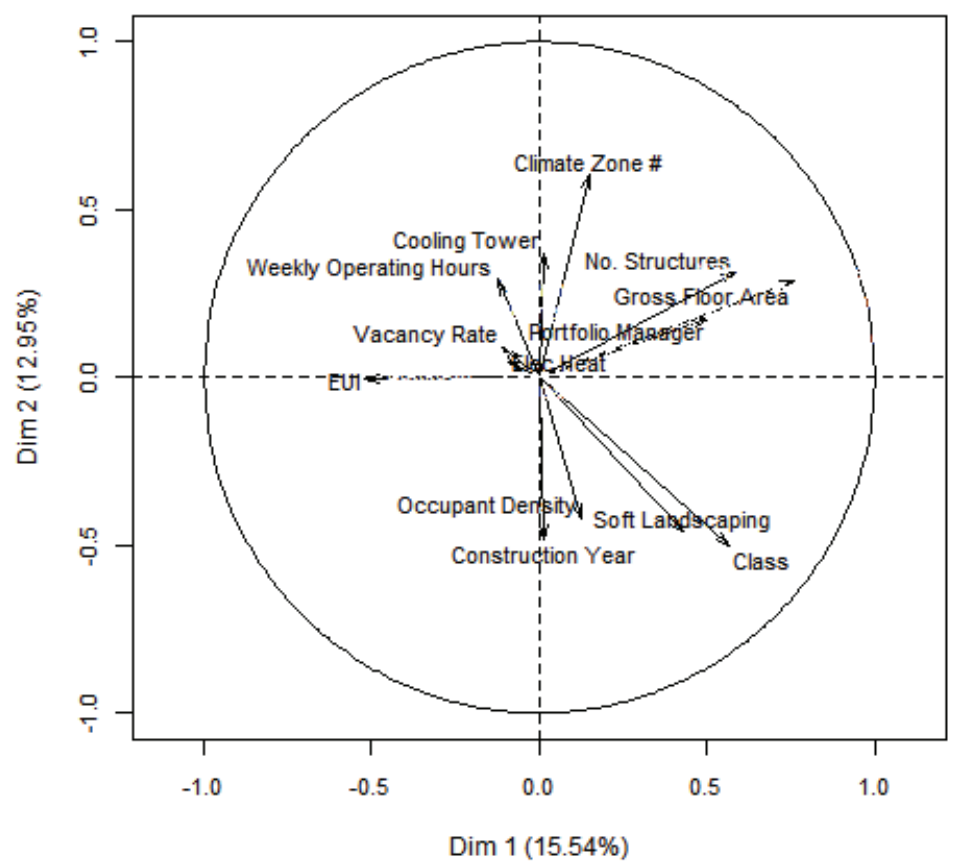


FUNCTION: PCASHINY, 2015 Dataset, Independent Input Variables: EUI, GFA+EP, L_L

Individuals factor map (PCA)

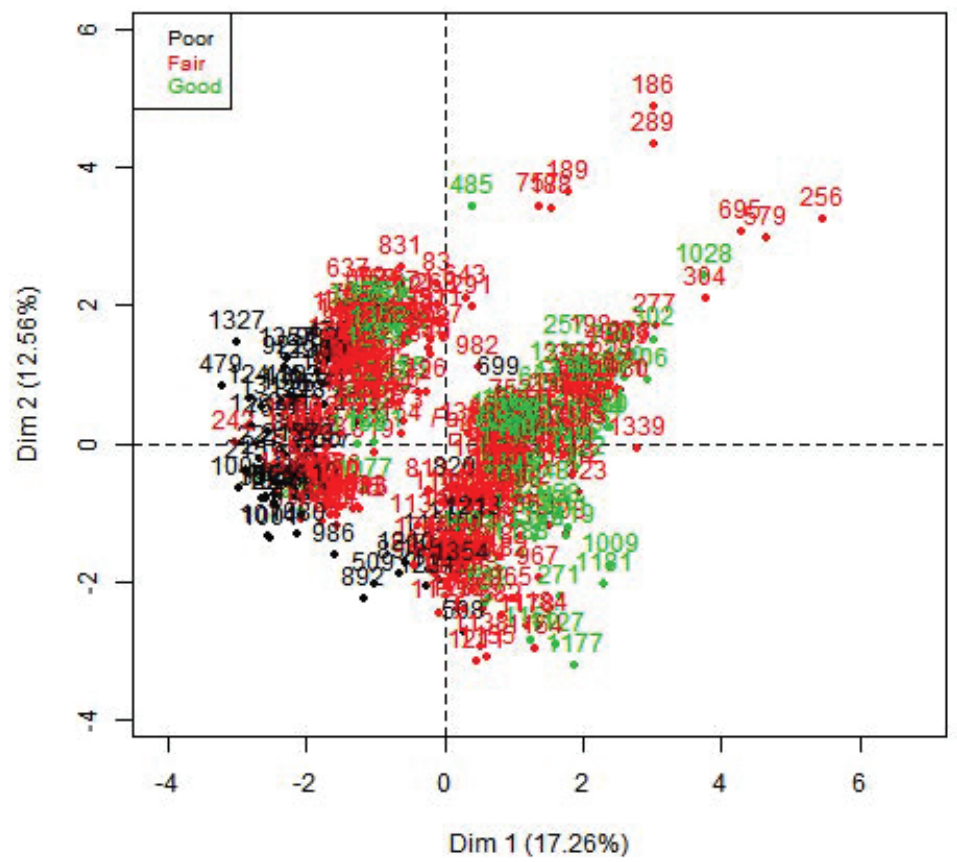

Variables factor map (PCA)

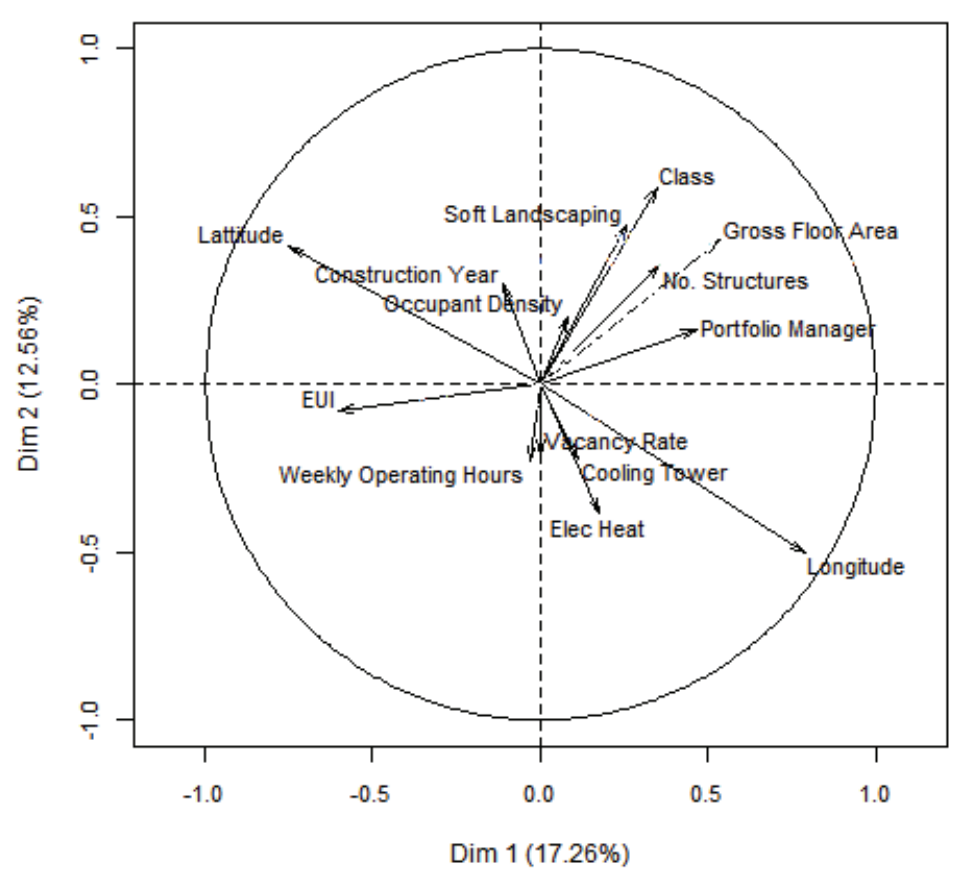


FUNCTION: PCASHINY, 2015 Dataset, Independent Input Variables: EUI, NRA, CZ

Individuals factor map (PCA)

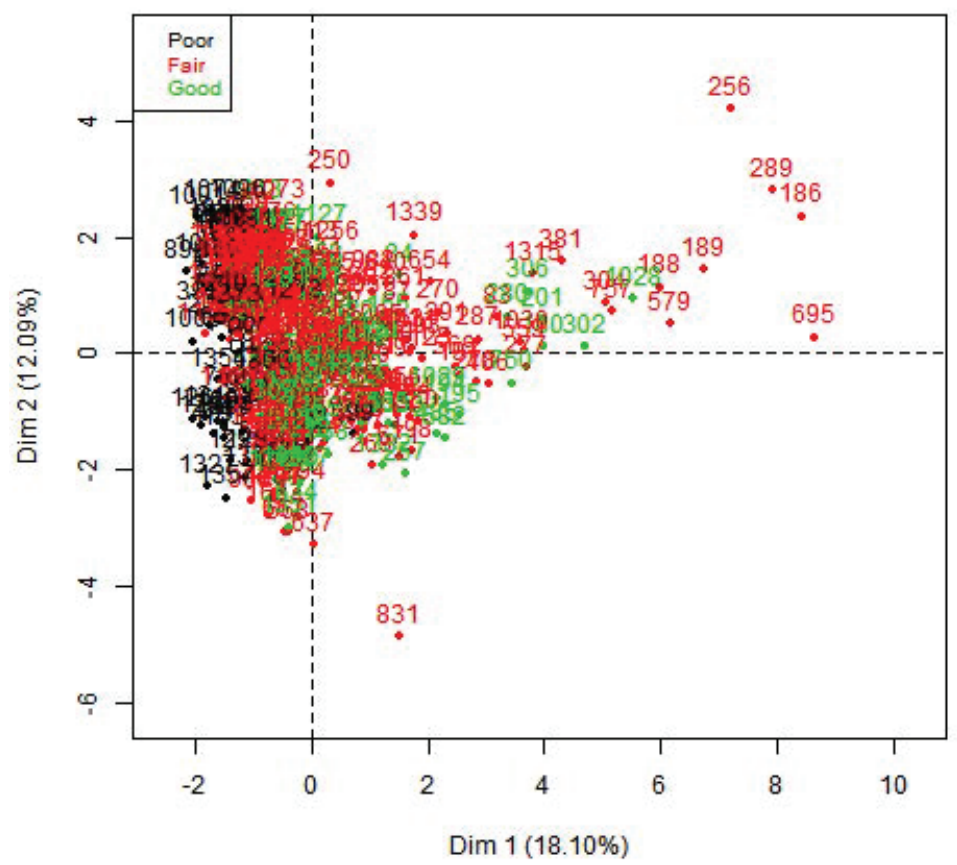

Variables factor map (PCA)

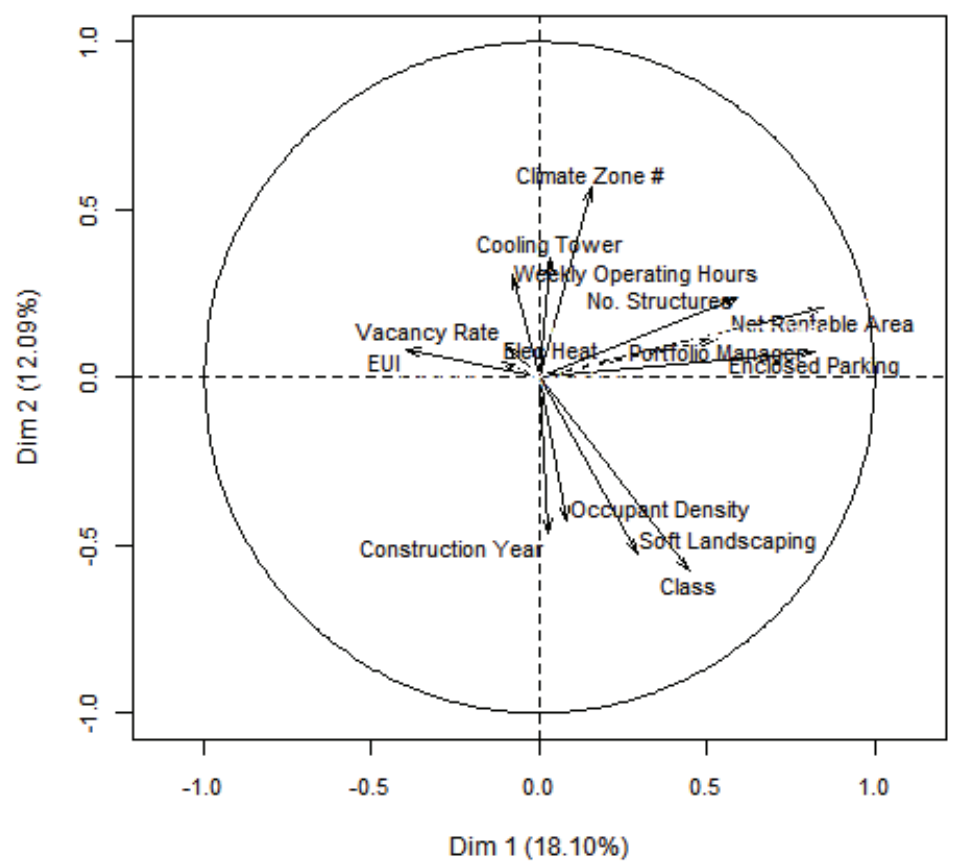


FUNCTION: PCASHINY, 2015 Dataset, Independent Input Variables: EUI, NRA, L_L

Individuals factor map (PCA)

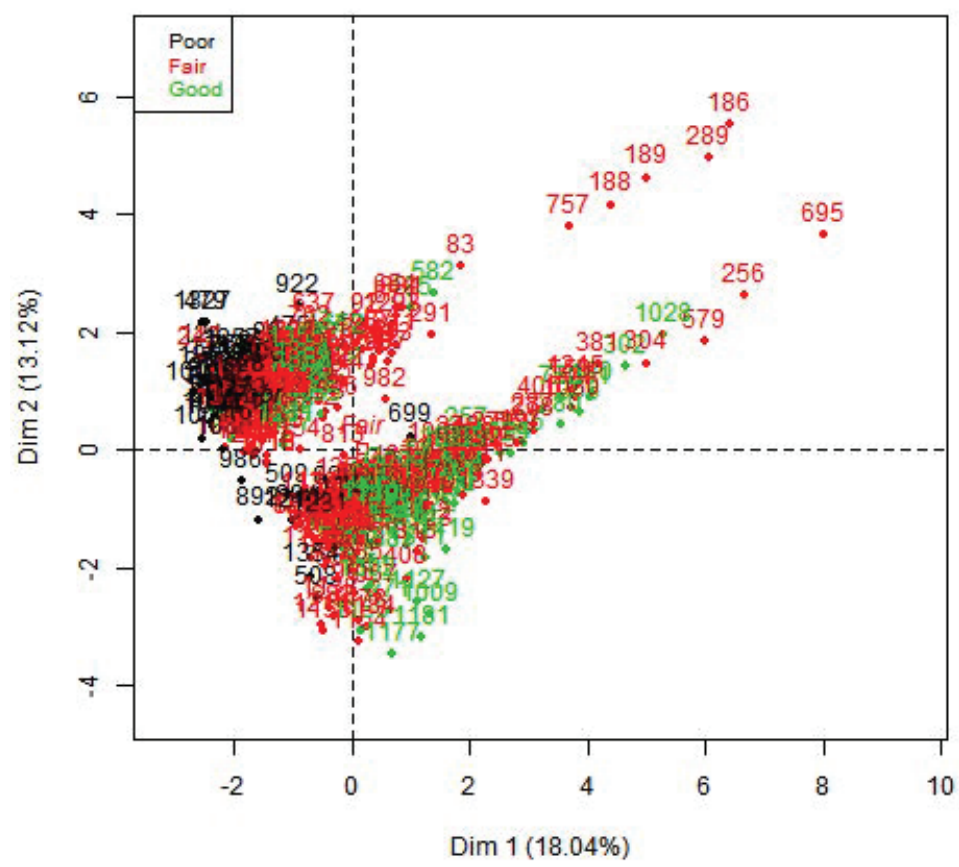

Variables factor map (PCA)

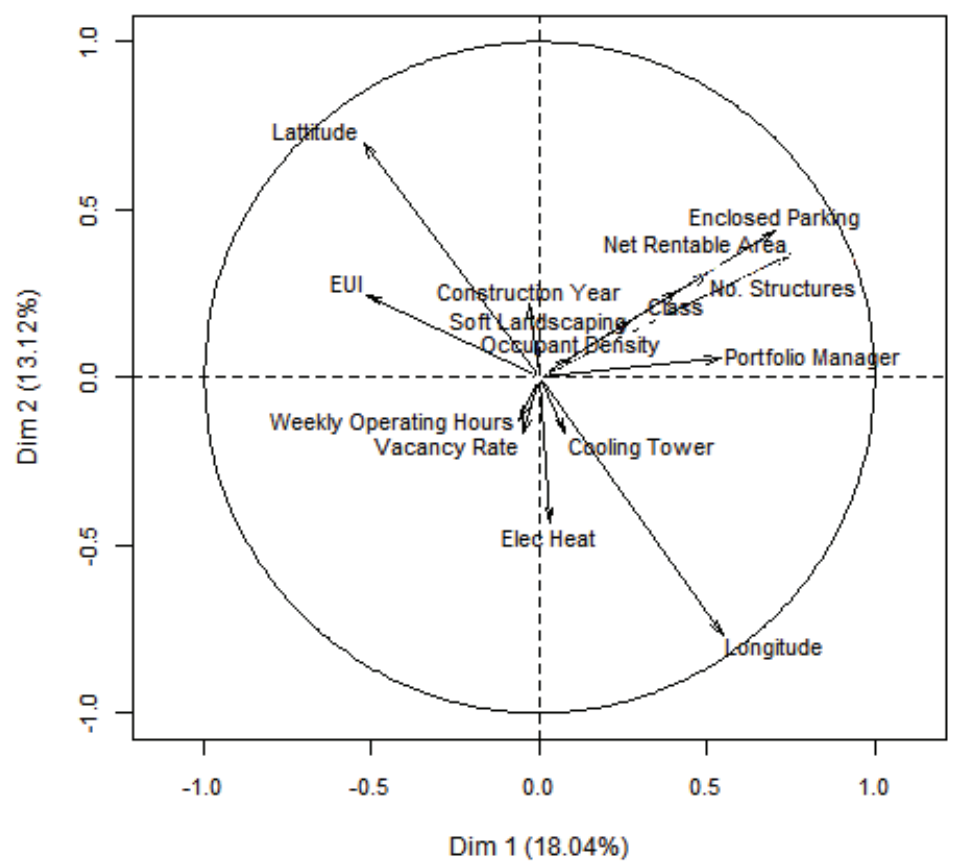


FUNCTION: PCASHINY, 2015 Dataset, Independent Input Variables: EUI, NRA+EP, CZ

Individuals factor map (PCA)

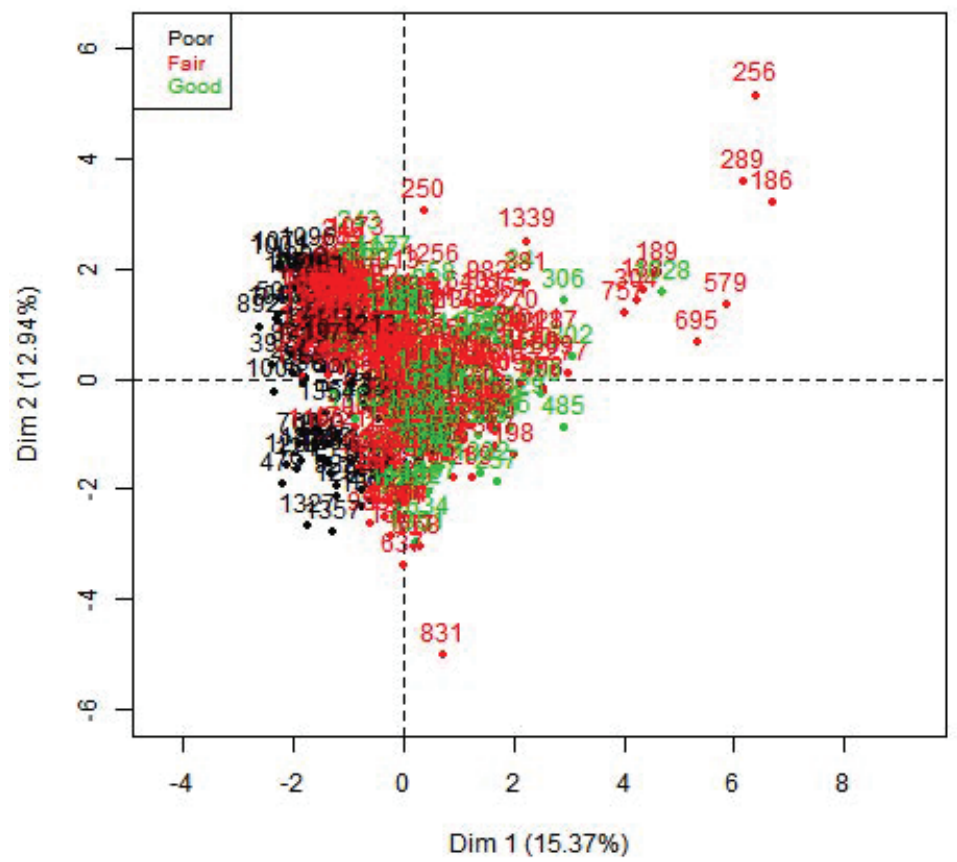

Variables factor map (PCA)

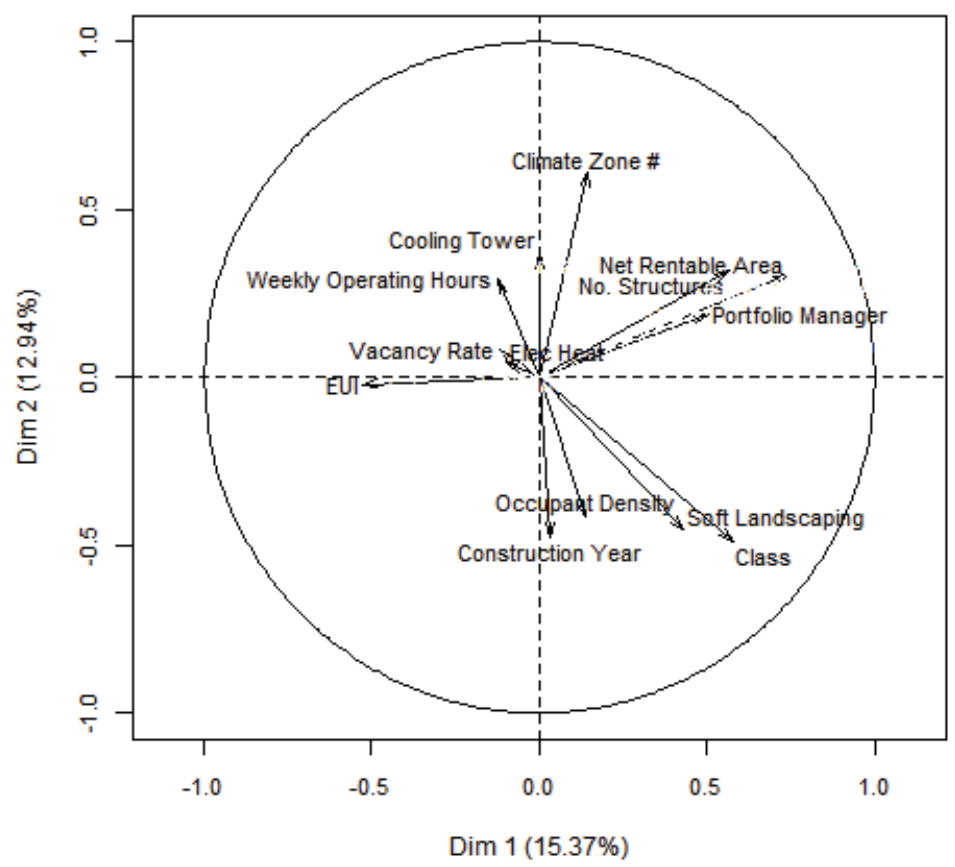


FUNCTION: PCASHINY, 2015 Dataset, Independent Input Variables: EUI, NRA+EP, L_L

Individuals factor map (PCA)

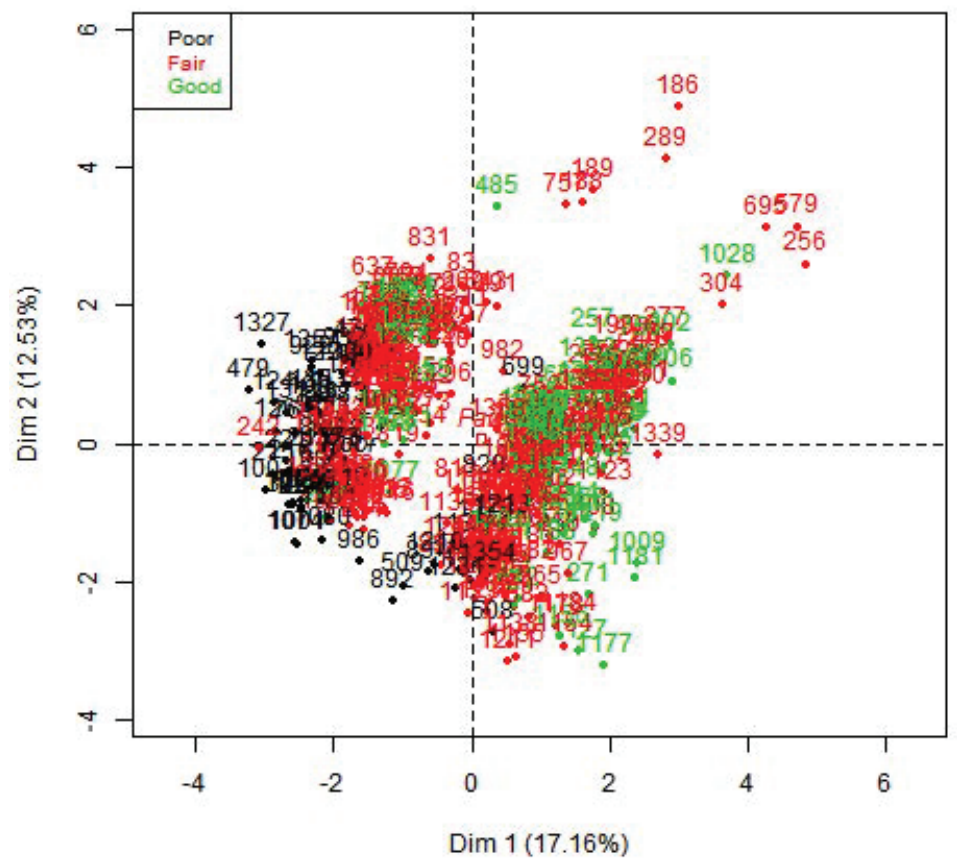

Variables factor map (PCA)

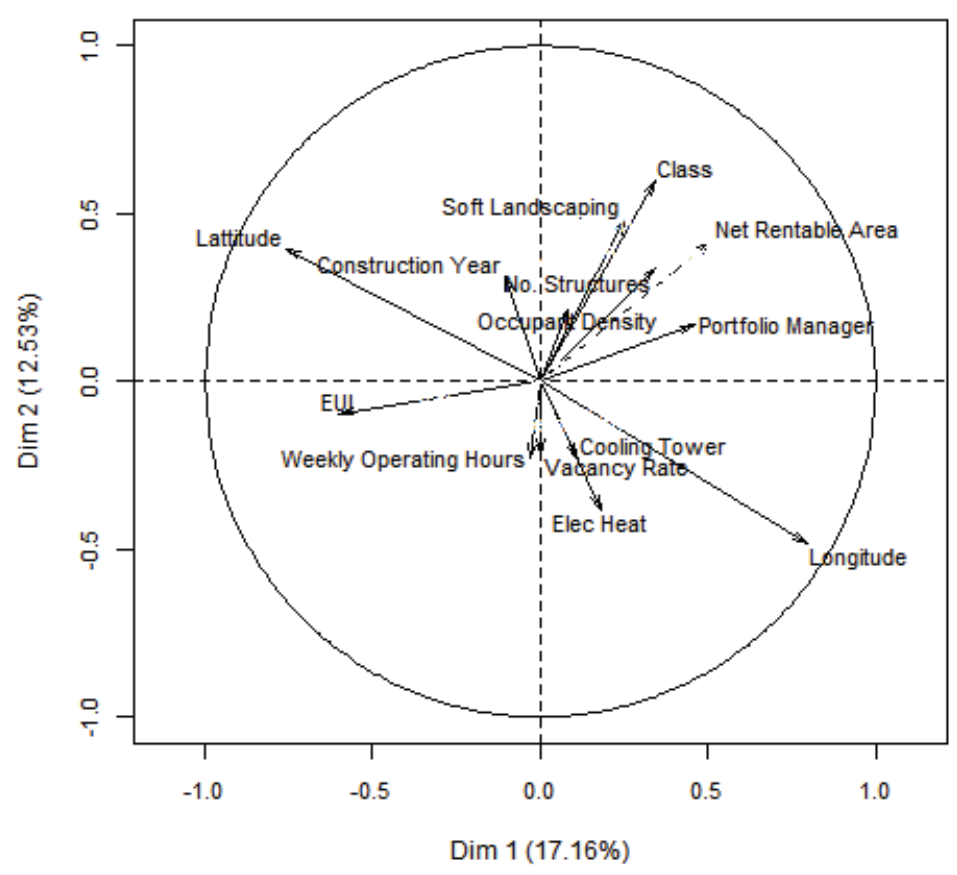


FUNCTION: PCASHINY, 2015 Dataset, Independent Input Variables: GFA, CZ

Individuals factor map (PCA)

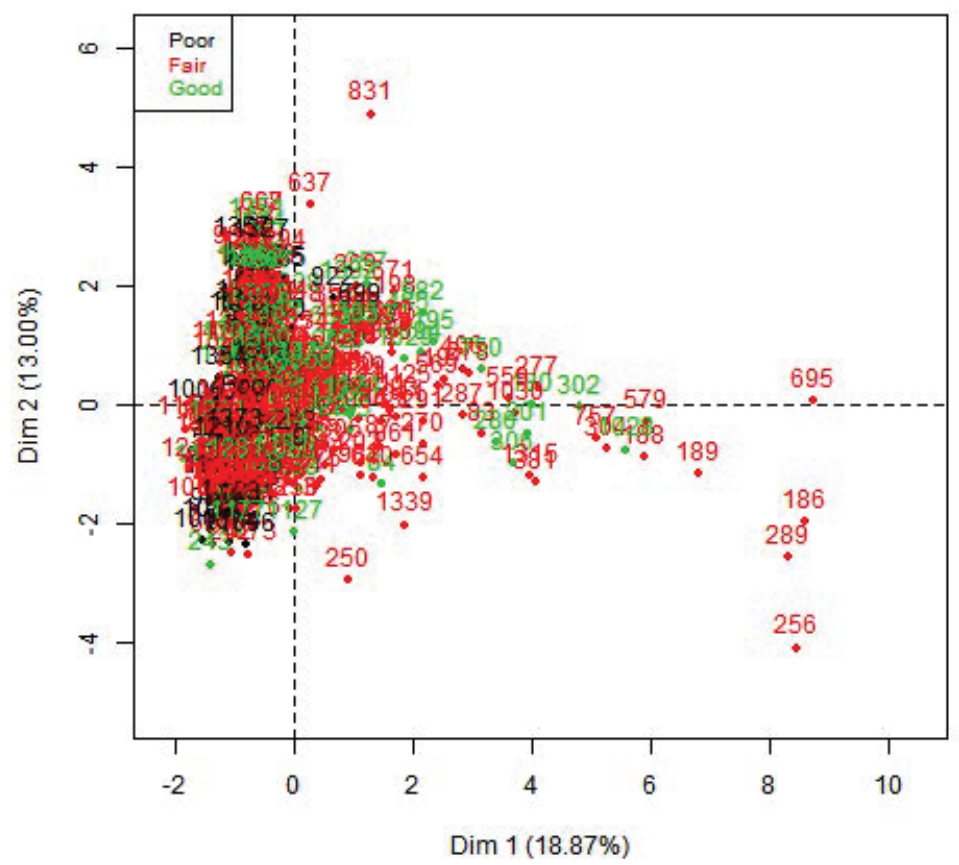

Variables factor map (PCA)

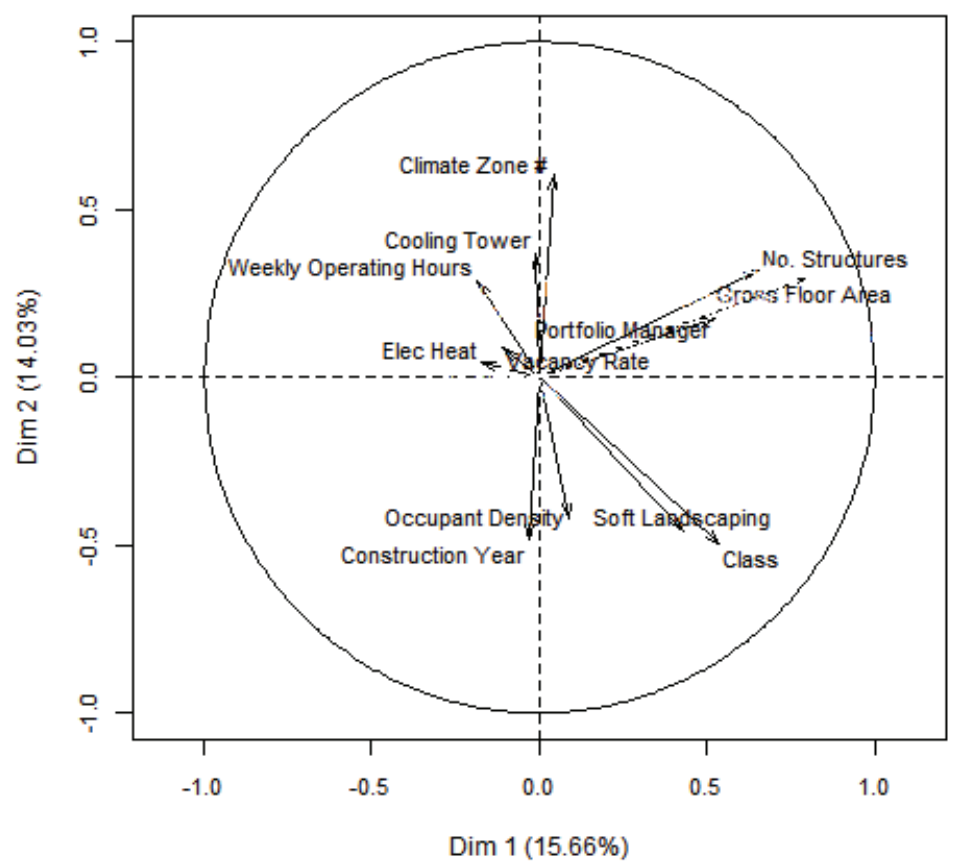


FUNCTION: PCASHINY, 2015 Dataset, Independent Input Variables: GFA, L_L

Individuals factor map (PCA)

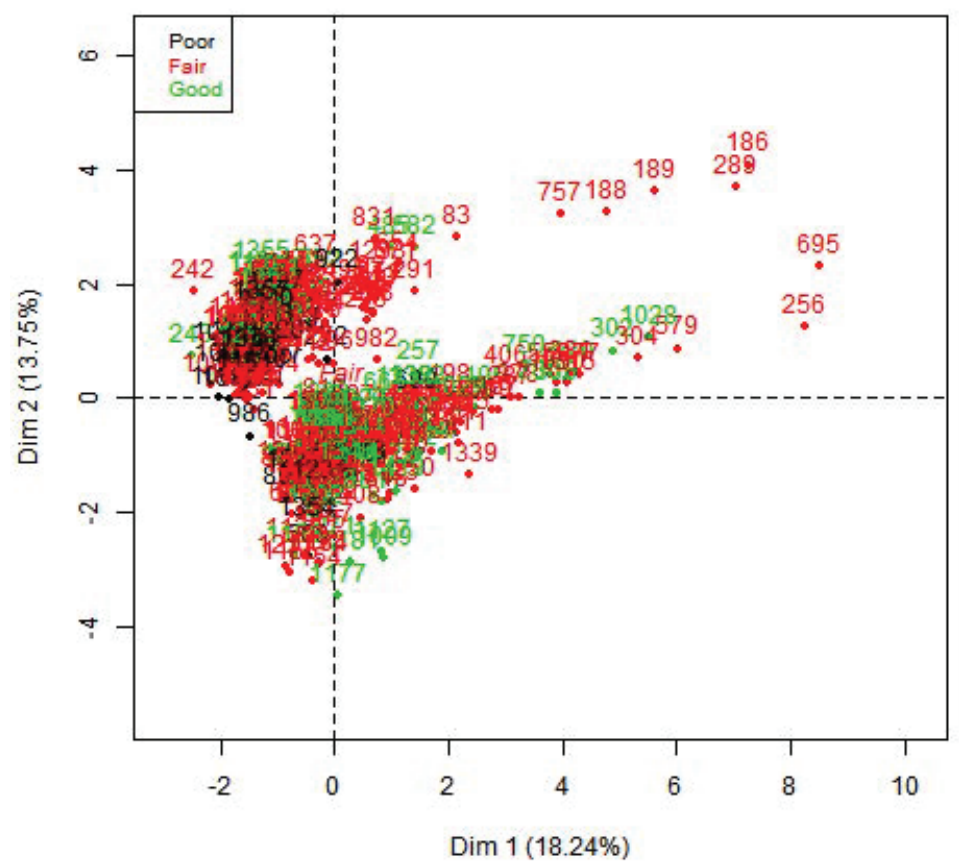

Variables factor map (PCA)

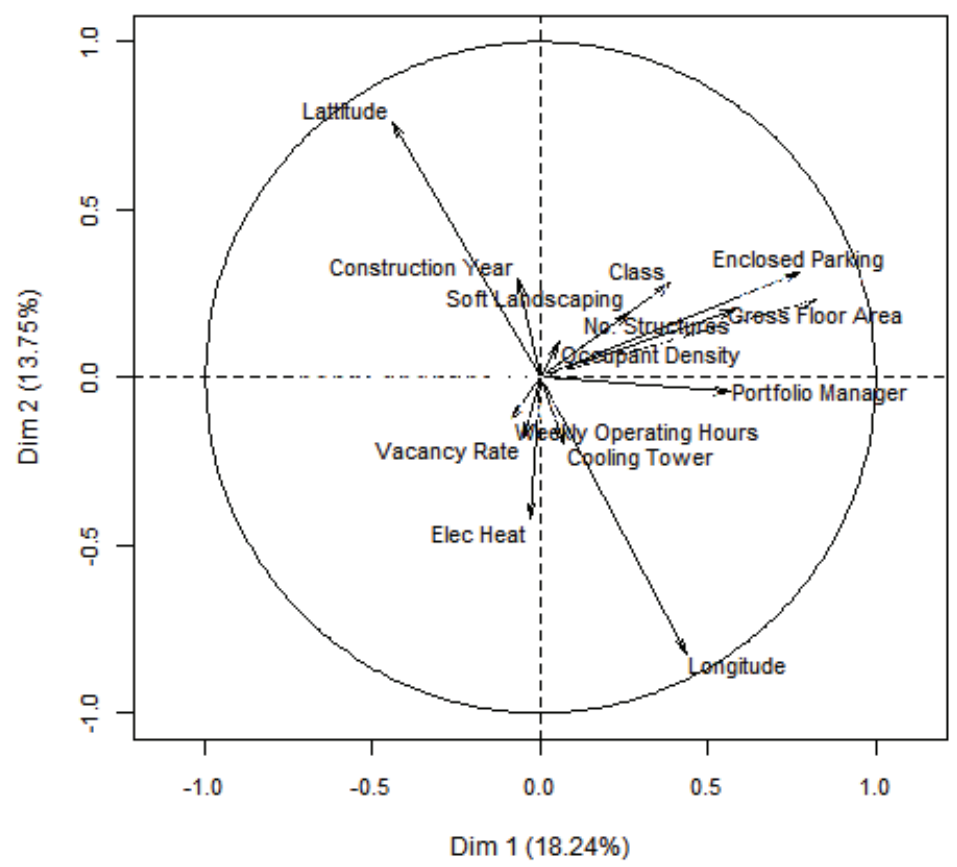


FUNCTION: PCASHINY, 2015 Dataset, Independent Input Variables: GFA+EP, CZ

Individuals factor map (PCA)

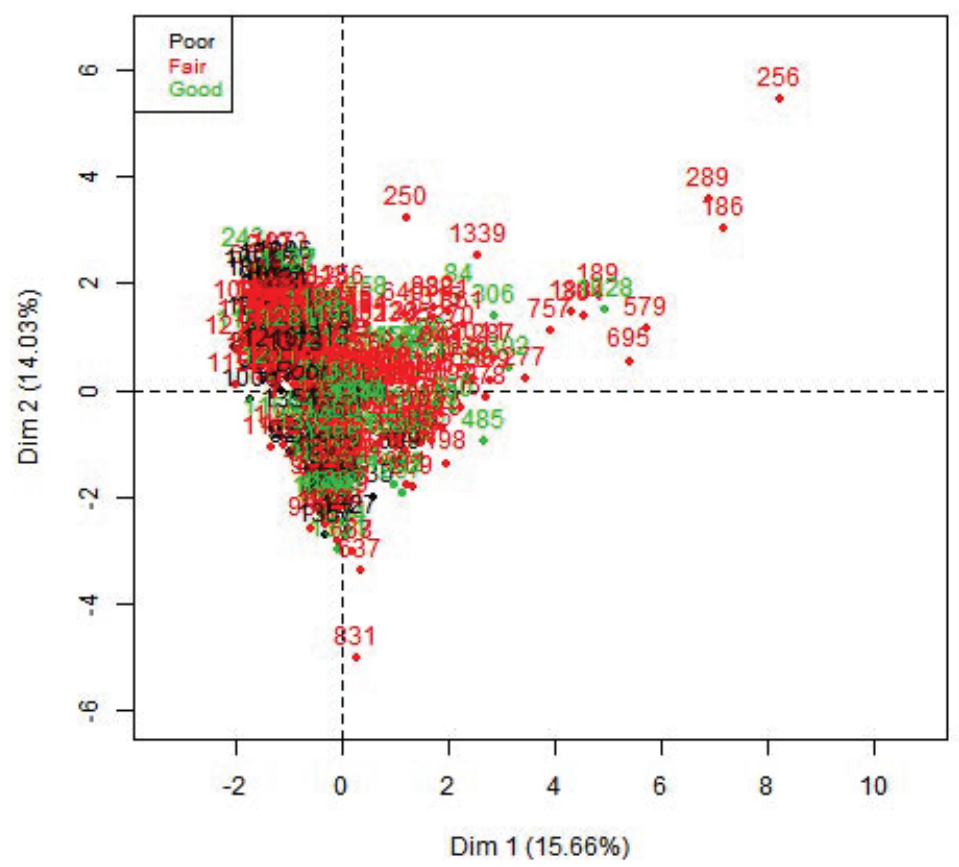

Variables factor map (PCA)

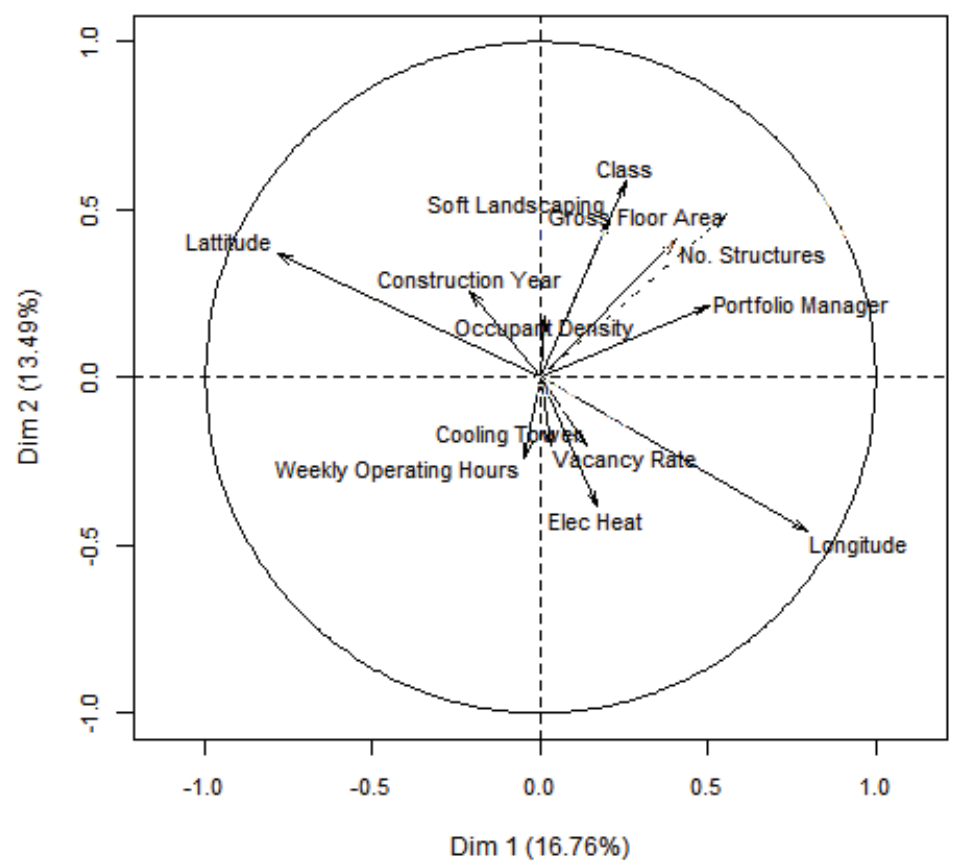


FUNCTION: PCASHINY, 2015 Dataset, Independent Input Variables: GFA+EP, L_L

Individuals factor map (PCA)

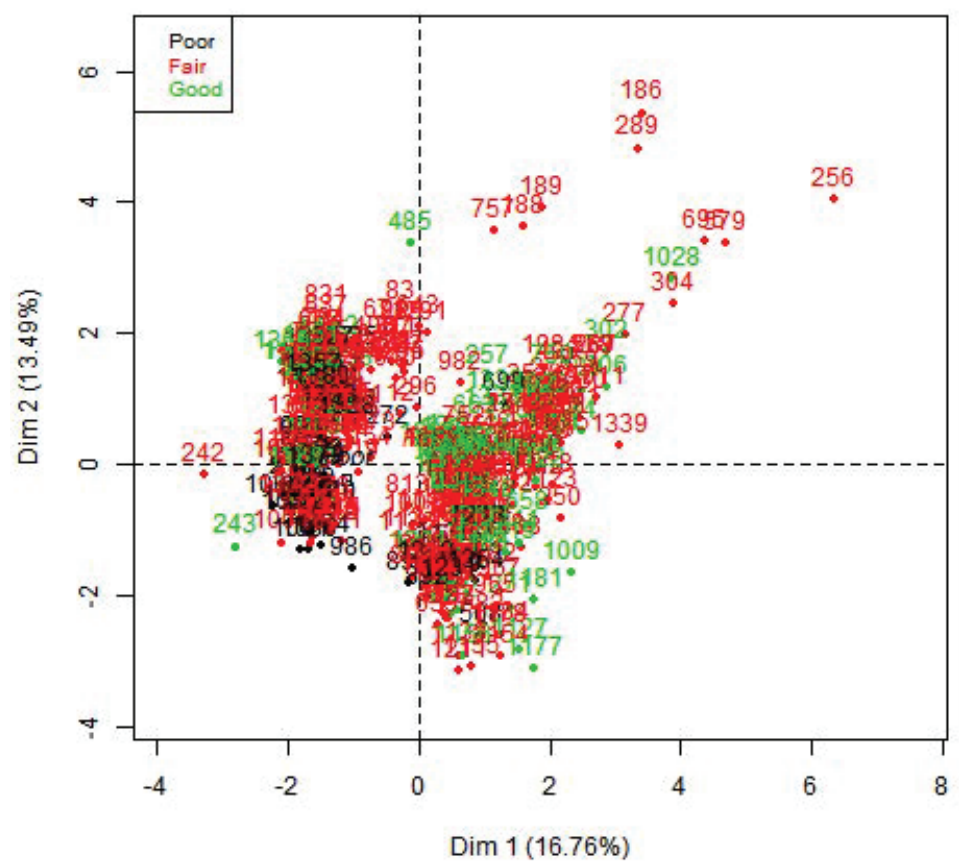

Variables factor map (PCA)

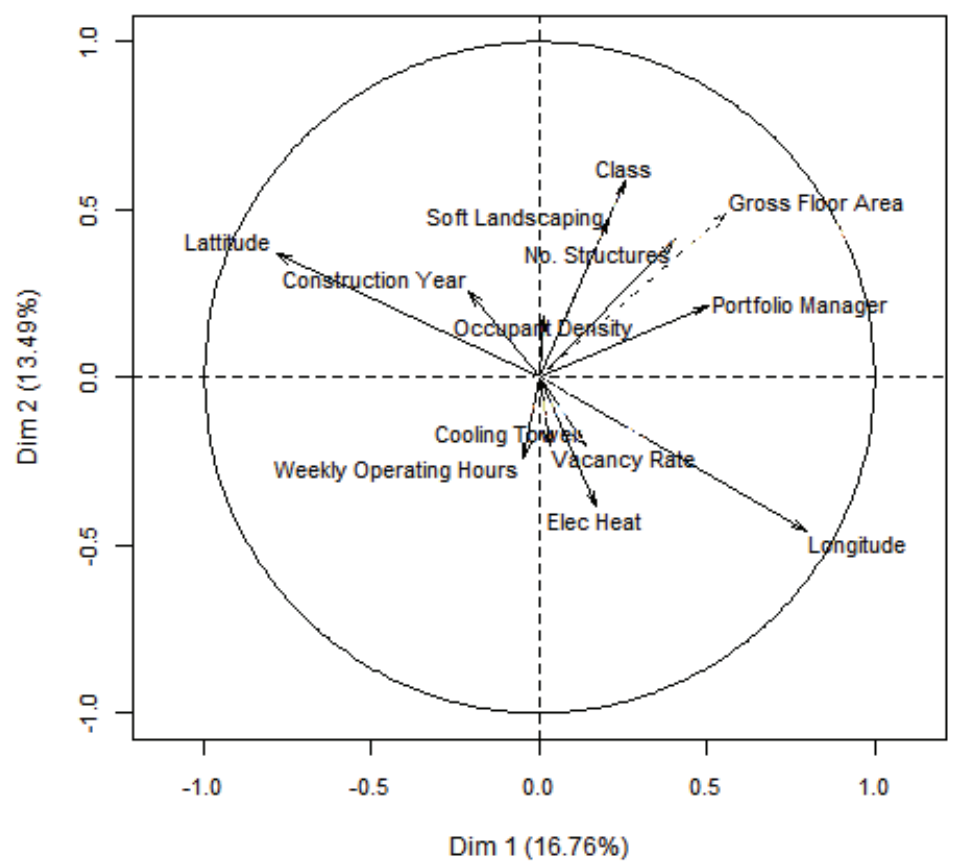


FUNCTION: PCASHINY, 2015 Dataset, Independent Input Variables: NRA+EP, L_L

Individuals factor map (PCA)

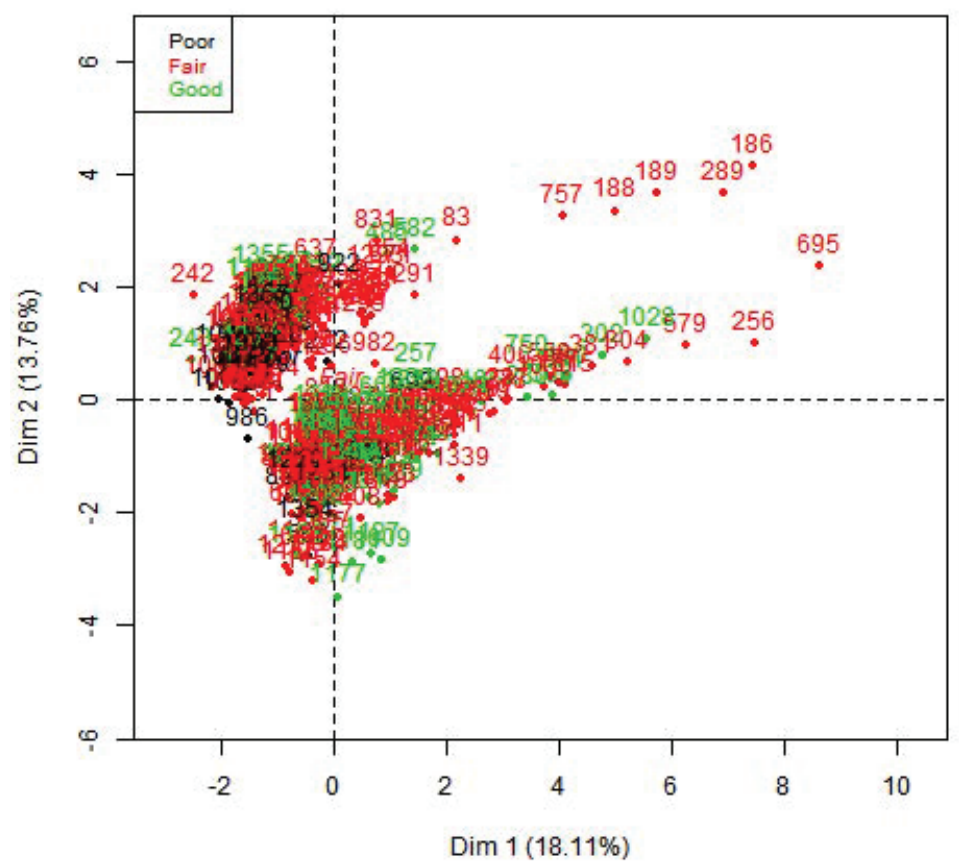

Variables factor map (PCA)

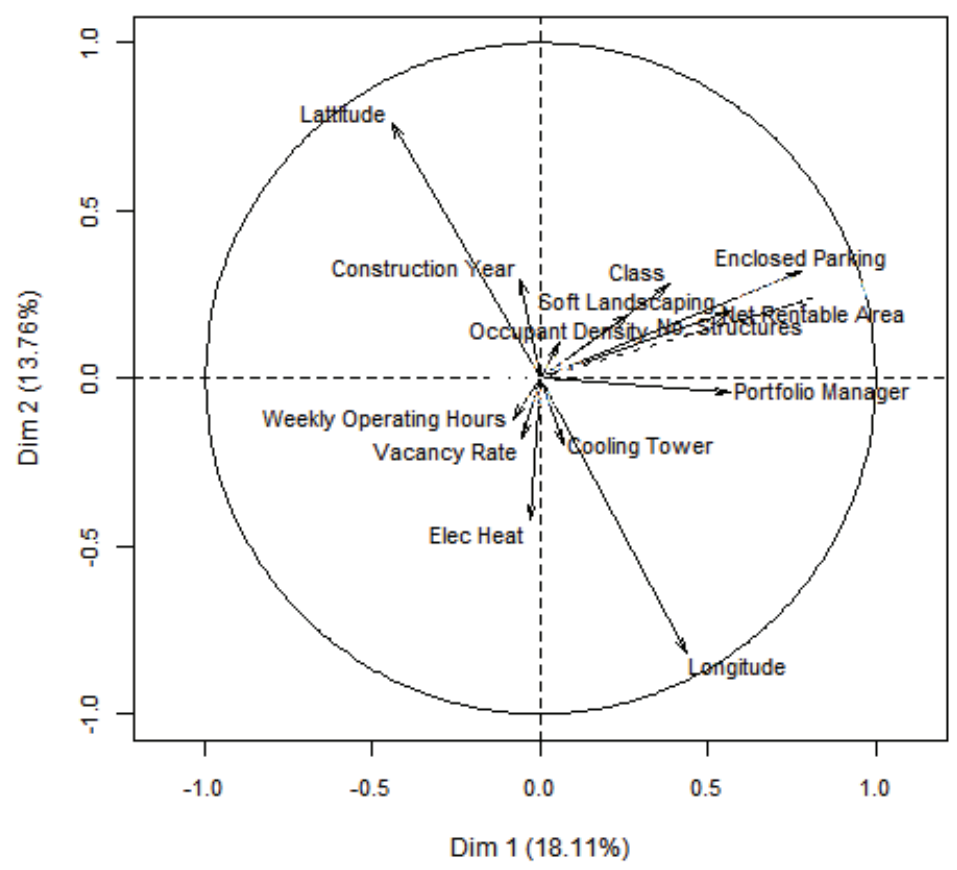


FUNCTION: PCASHINY, 2015 Dataset, Independent Input Variables: NRA, CZ

Individuals factor map (PCA)

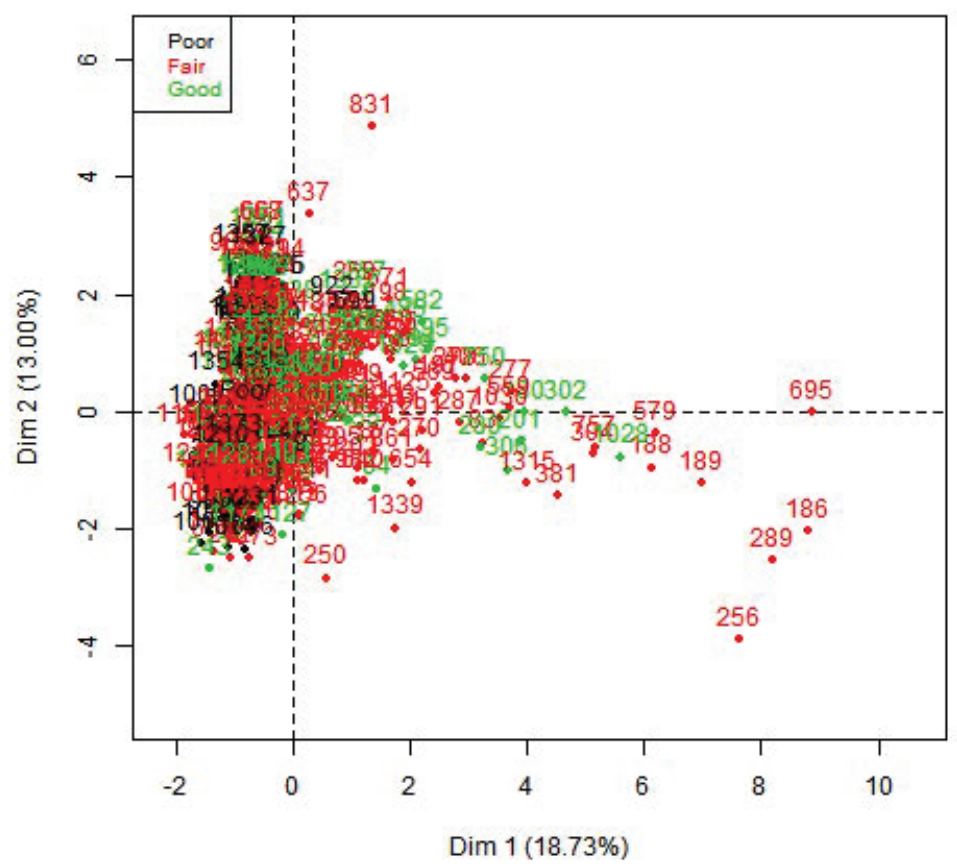

Variables factor map (PCA)

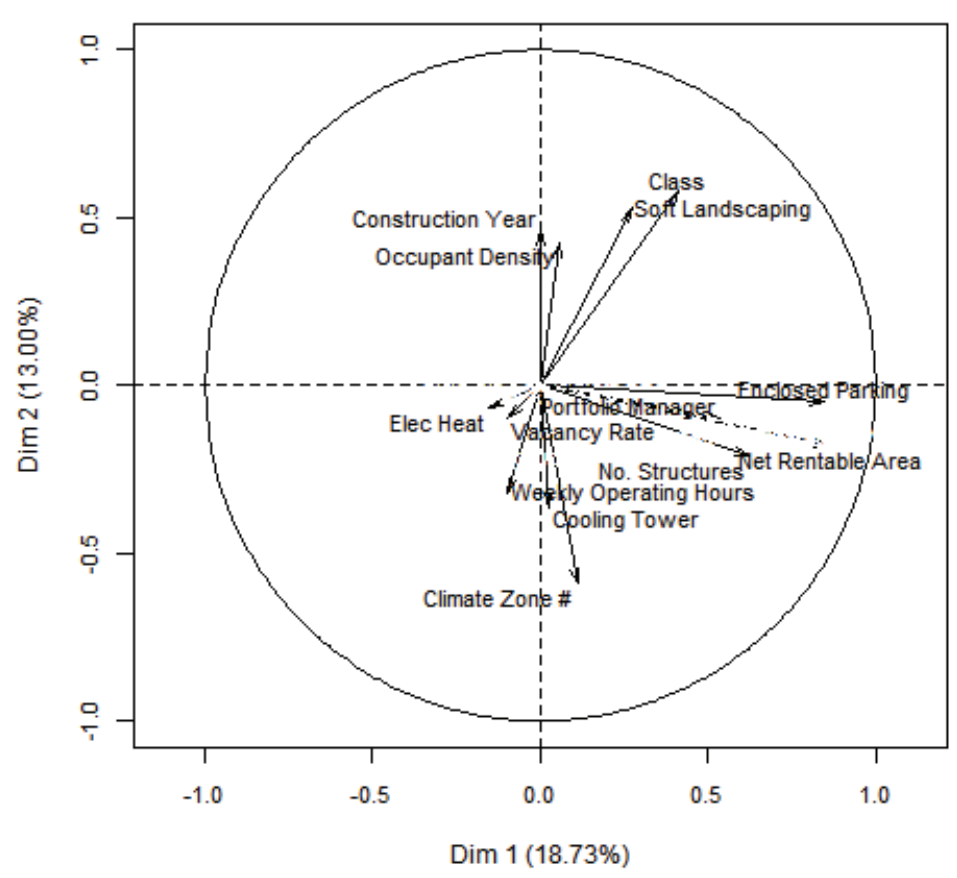


FUNCTION: PCASHINY, 2015 Dataset, Independent Input Variables: NRA+EP, CZ

Individuals factor map (PCA)

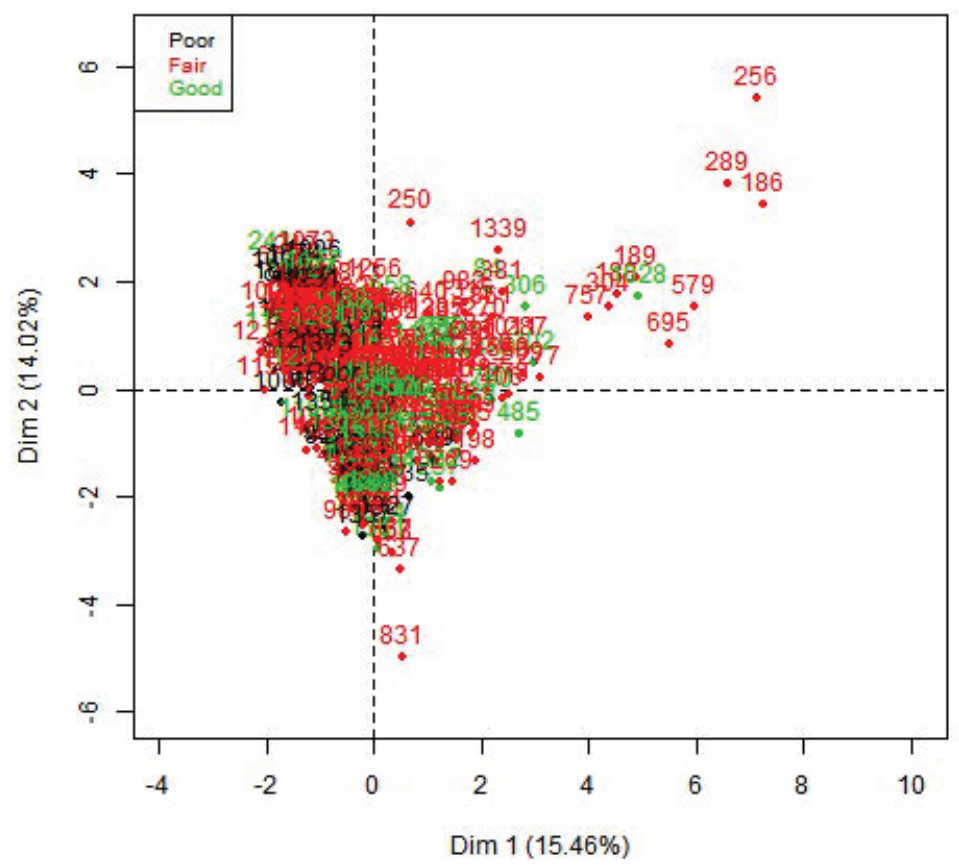

Variables factor map (PCA)

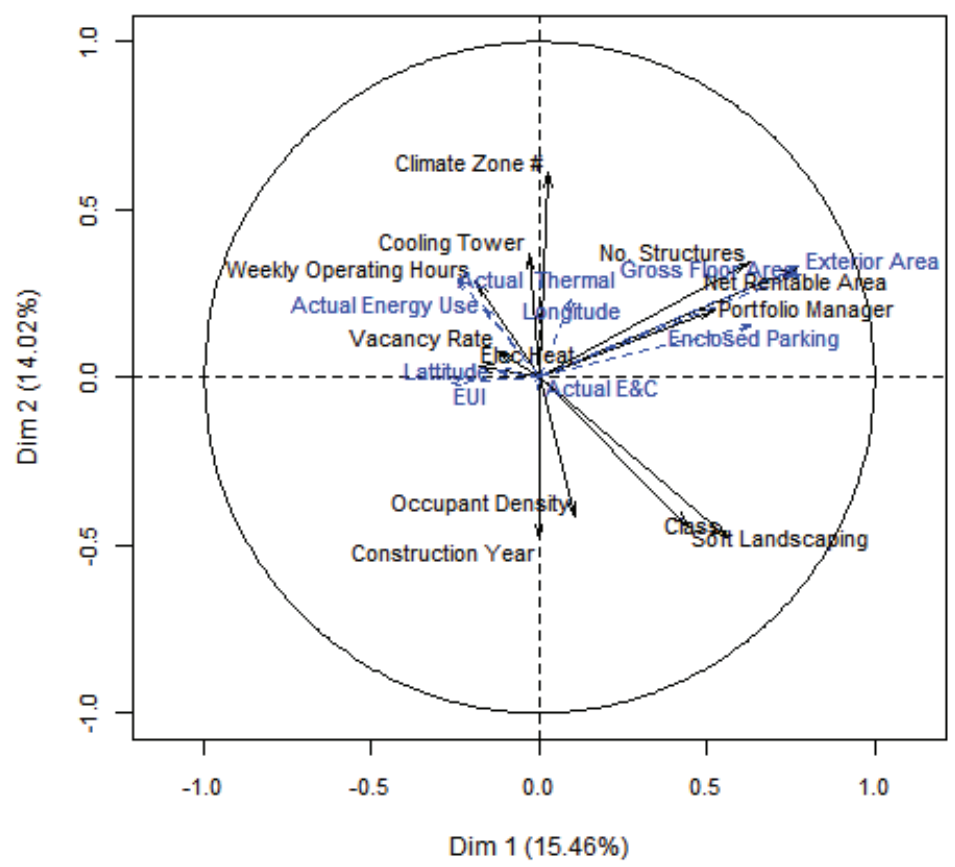


FUNCTION: PCASHINY, 2015 Dataset, Independent Input Variables: NRA, L_L

Individuals factor map (PCA)

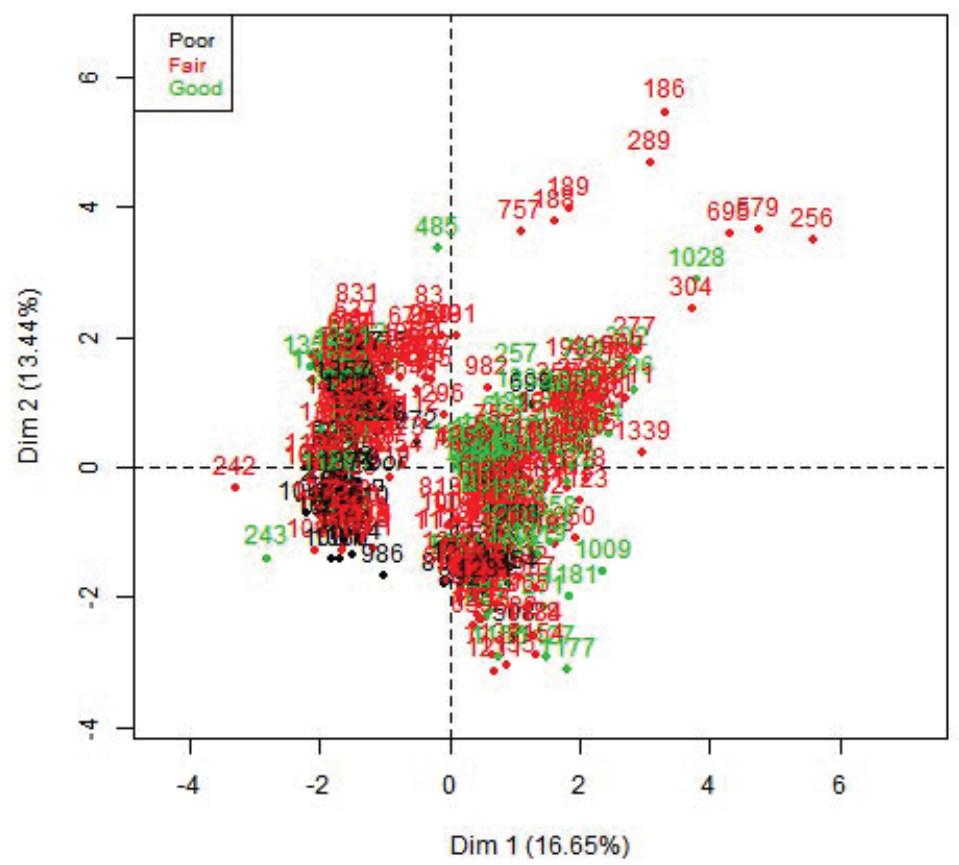

Variables factor map (PCA)

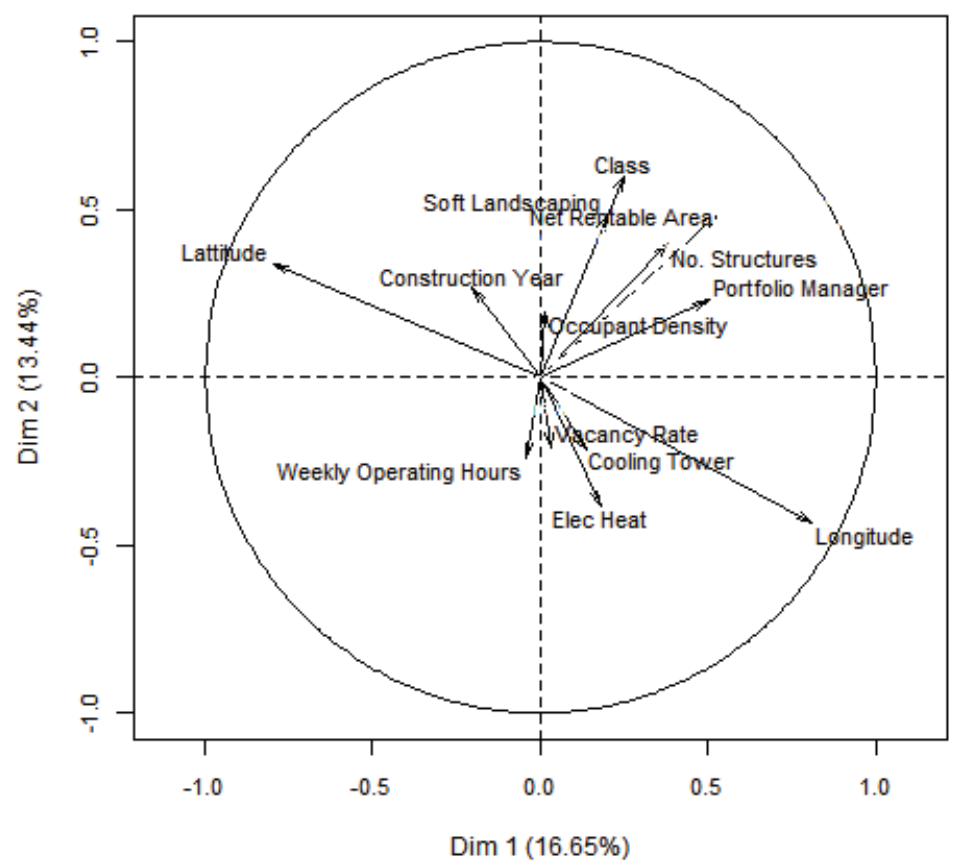


FUNCTION: PCASHINY, 2015 Dataset, Independent Input Variables: Th+EC, EA, CZ

Individuals factor map (PCA)

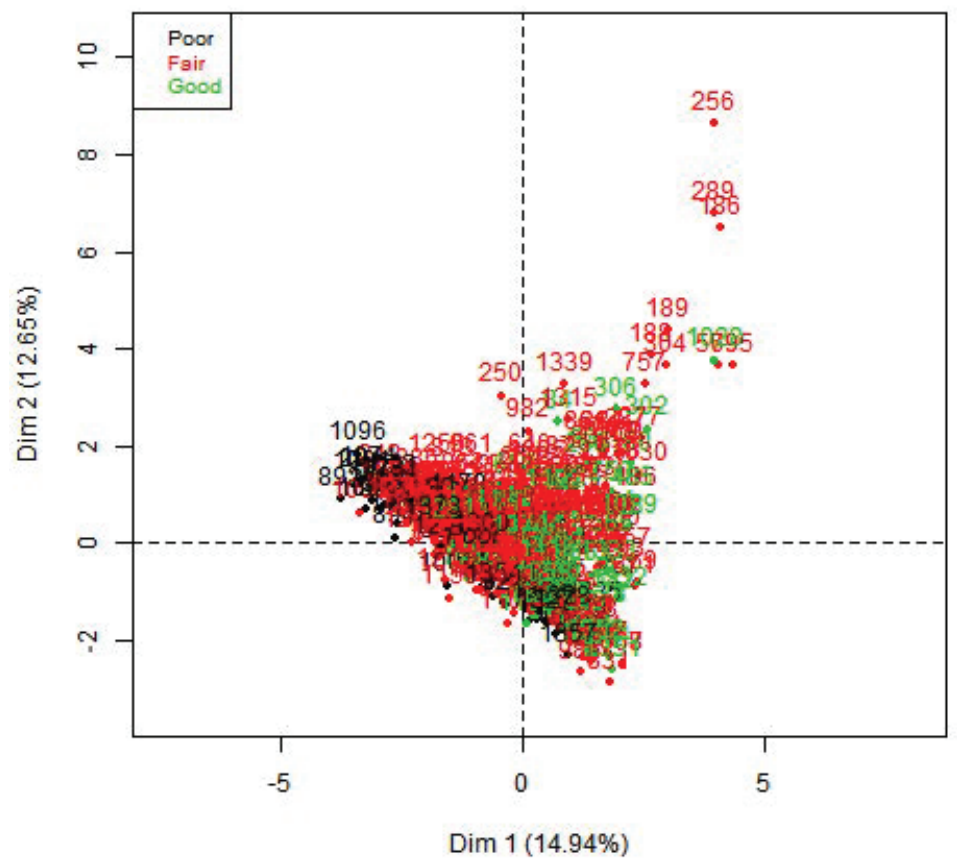

Variables factor map (PCA)

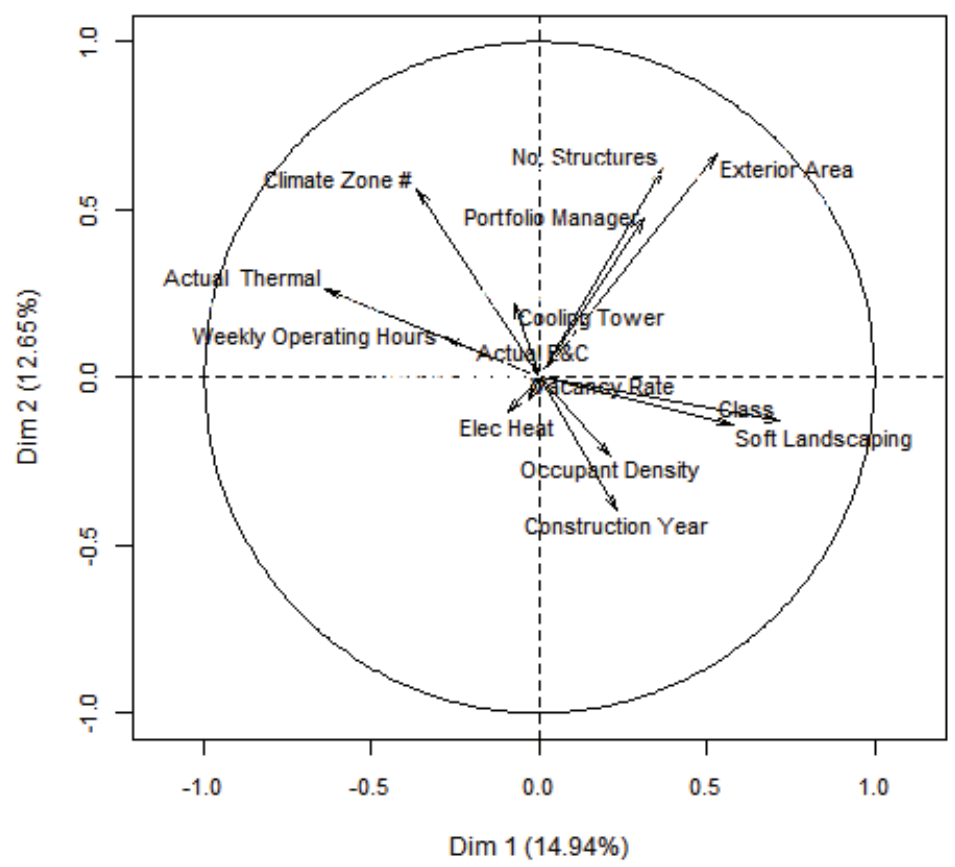


FUNCTION: PCASHINY, 2015 Dataset, Independent Input Variables: Th+EC, EA, L_L

Individuals factor map (PCA)

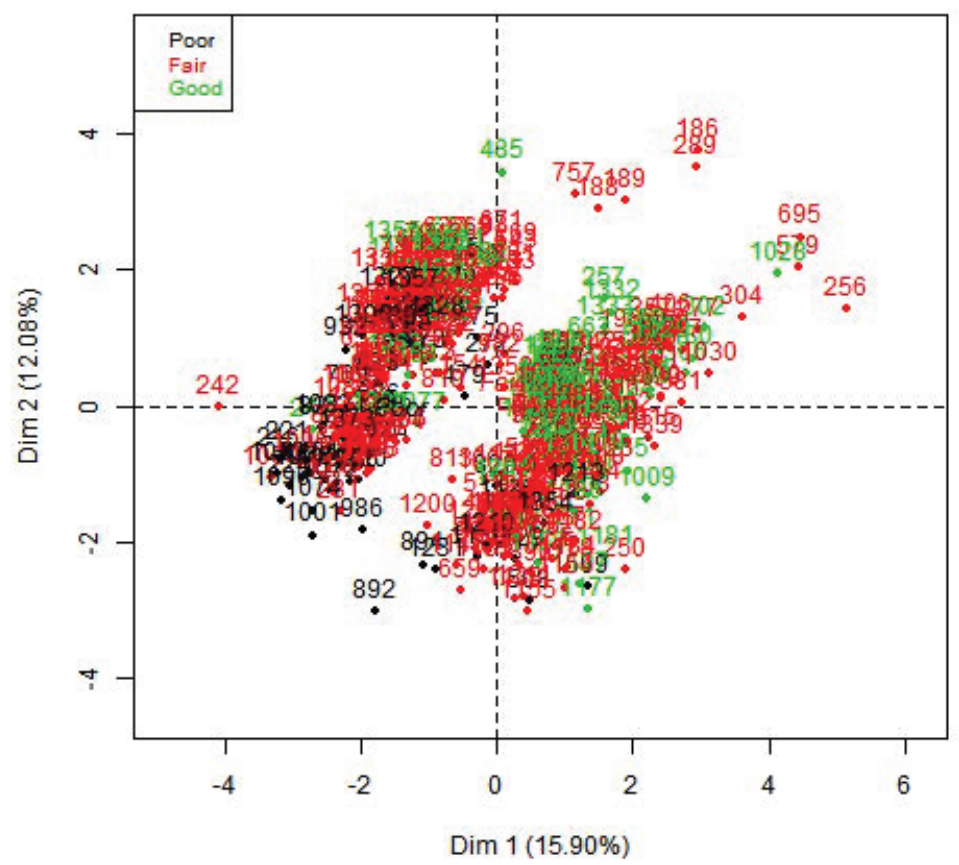

Variables factor map (PCA)

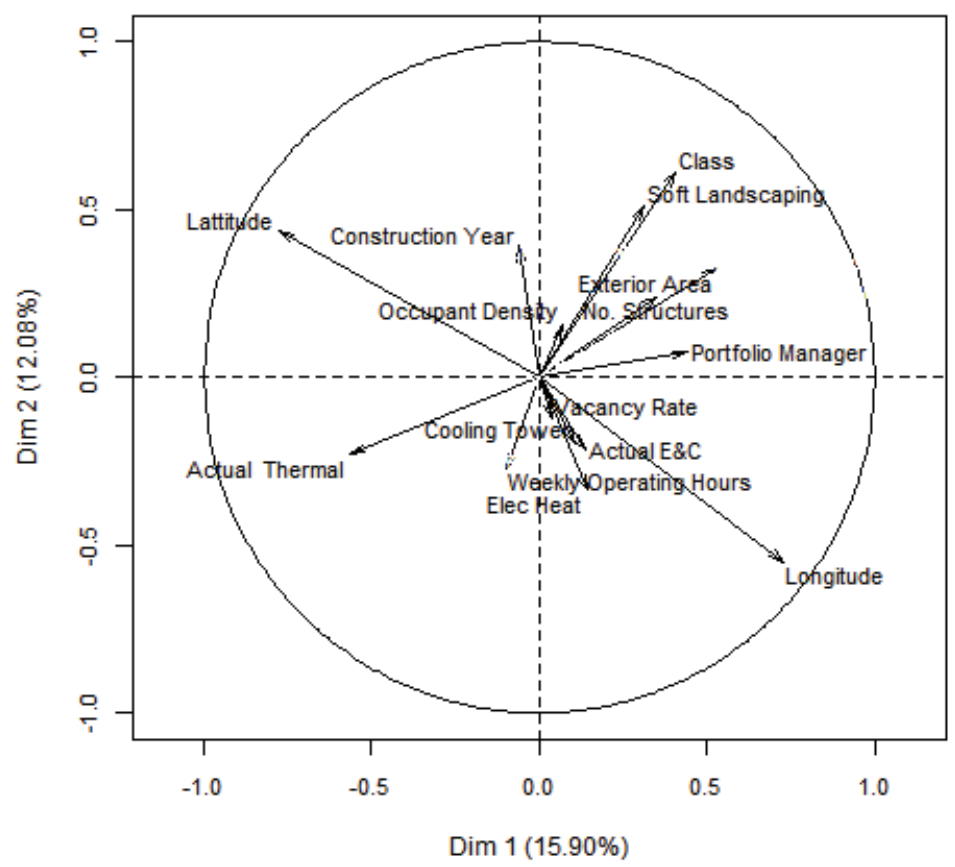


FUNCTION: PCASHINY, 2015 Dataset, Independent Input Variables: Th+EC, GFA, CZ

Individuals factor map (PCA)

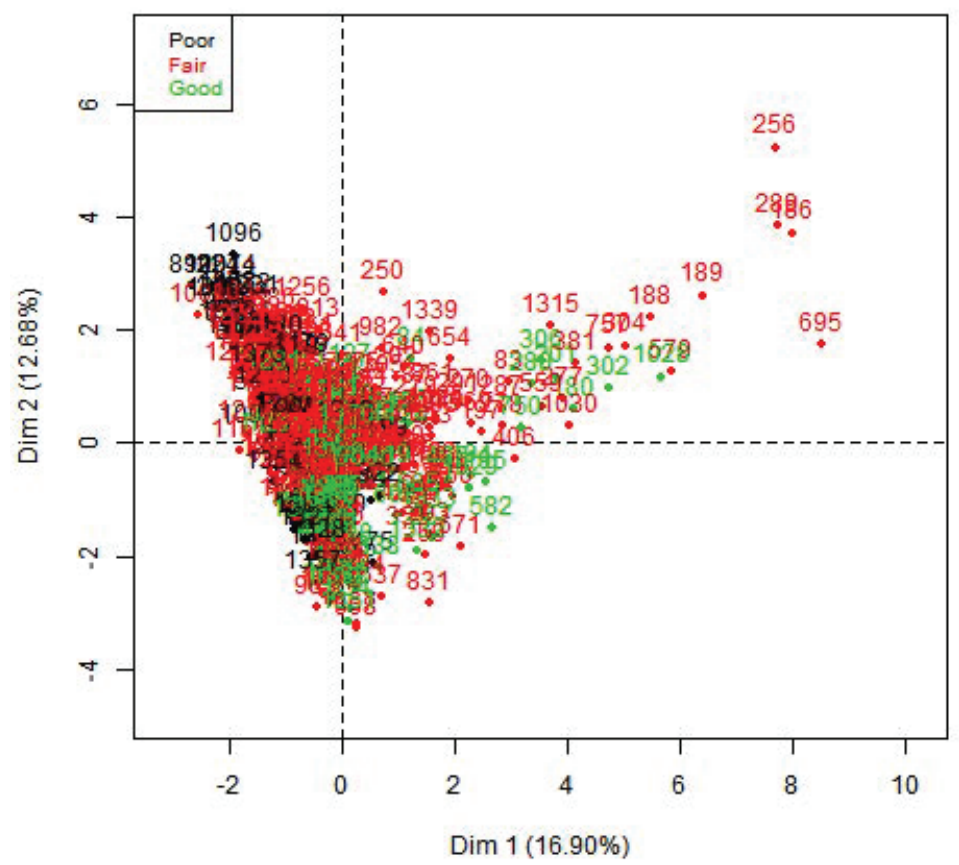

Variables factor map (PCA)

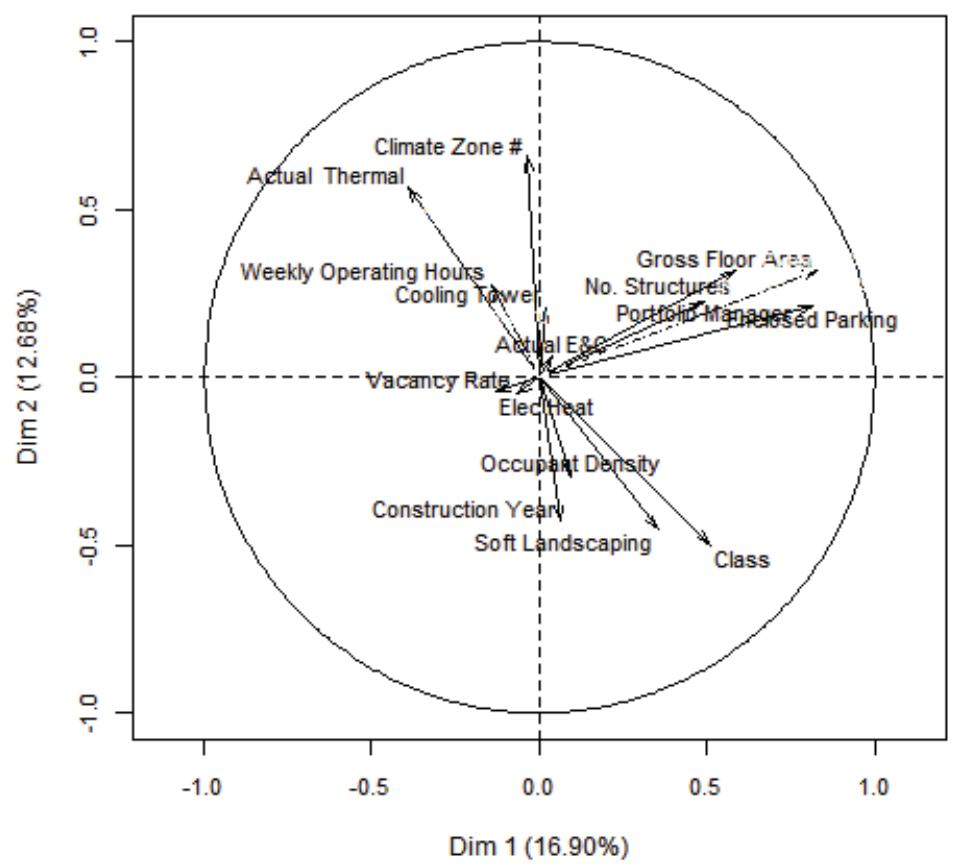


FUNCTION: PCASHINY, 2015 Dataset, Independent Input Variables: Th+EC, GFA, L_L

Individuals factor map (PCA)

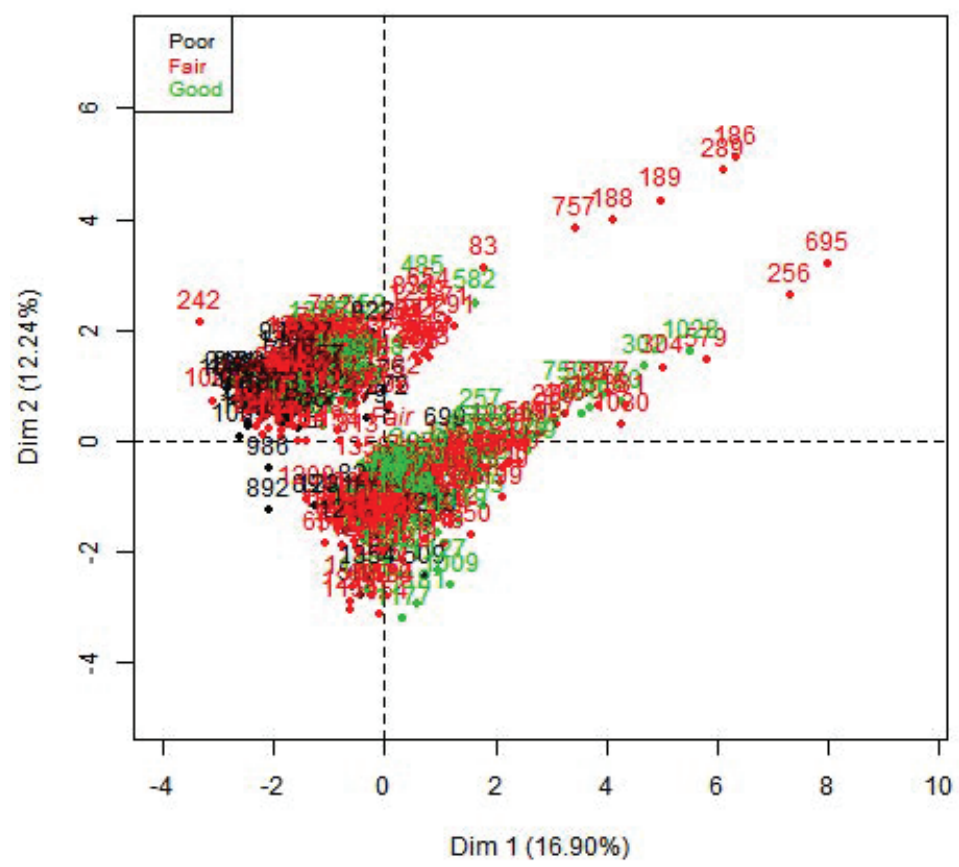

Variables factor map (PCA)

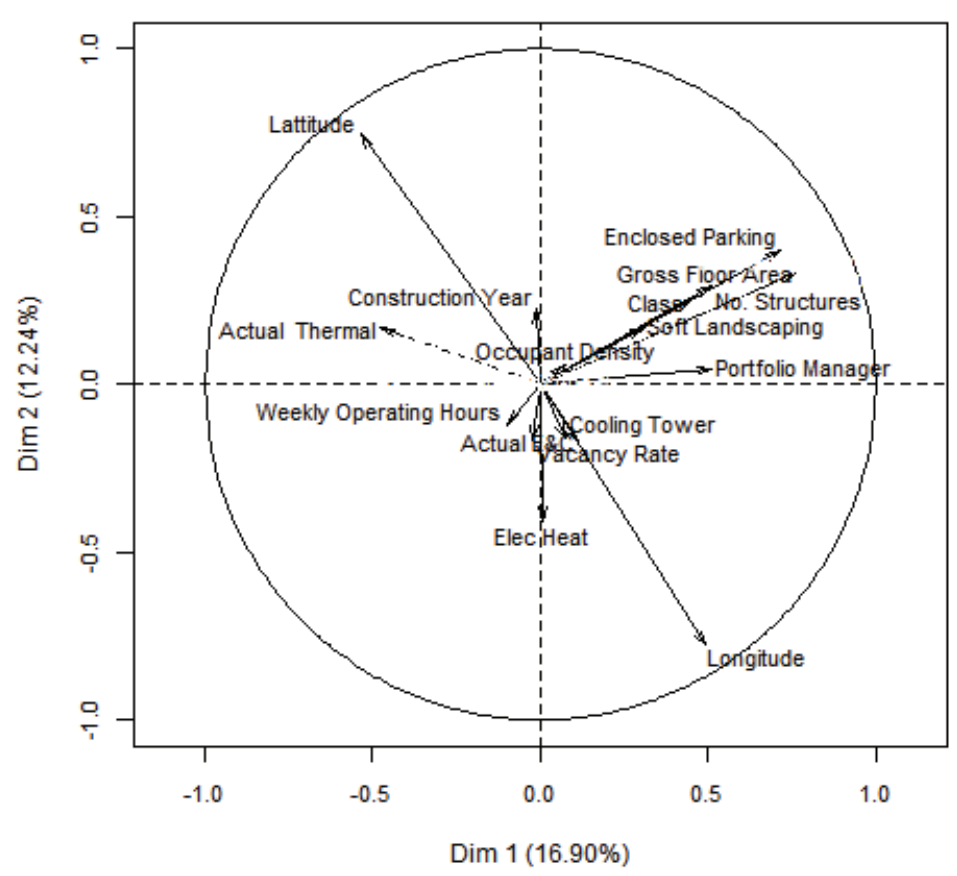



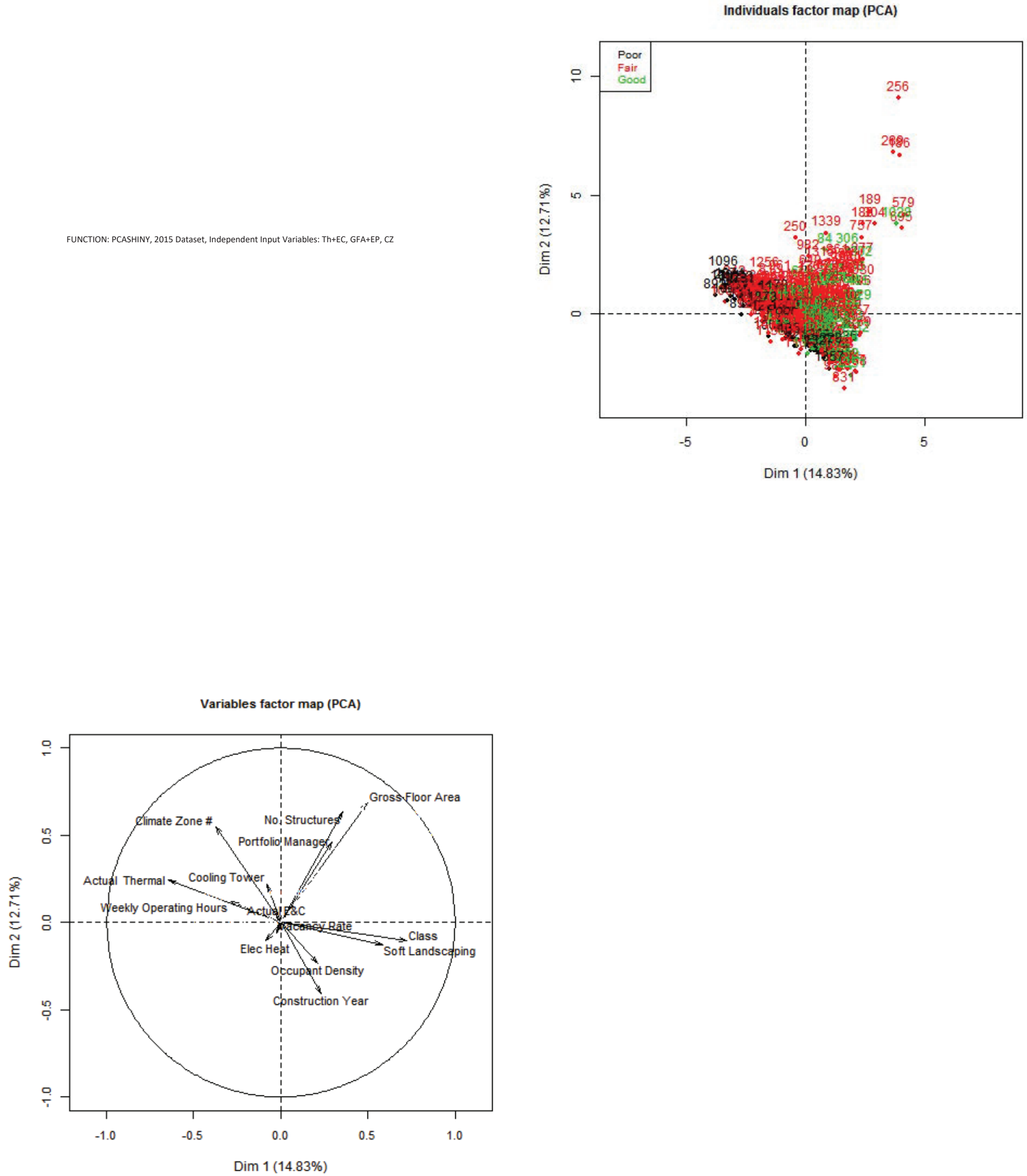

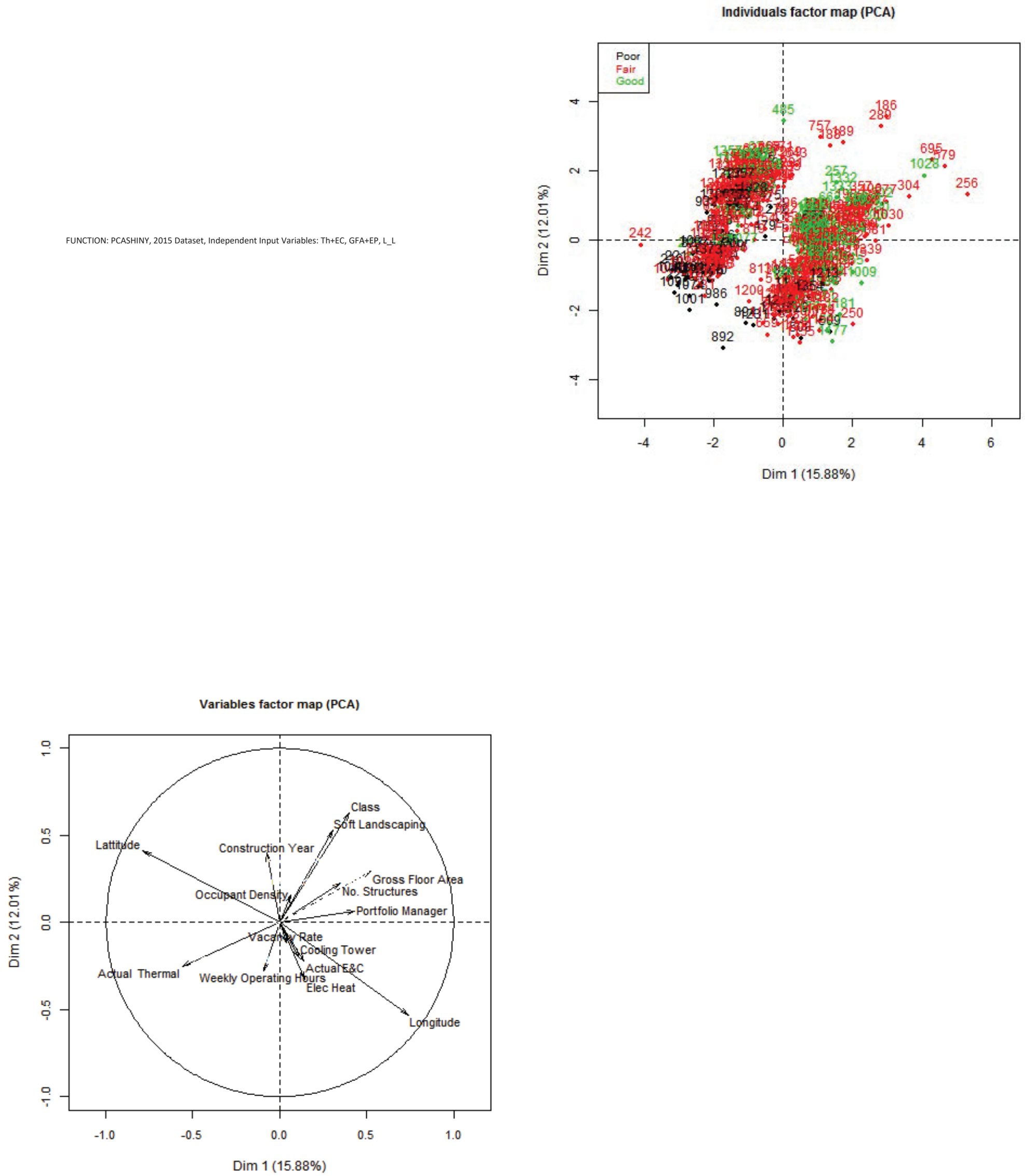
FUNCTION: PCASHINY, 2015 Dataset, Independent Input Variables: Th+EC, NRA, CZ
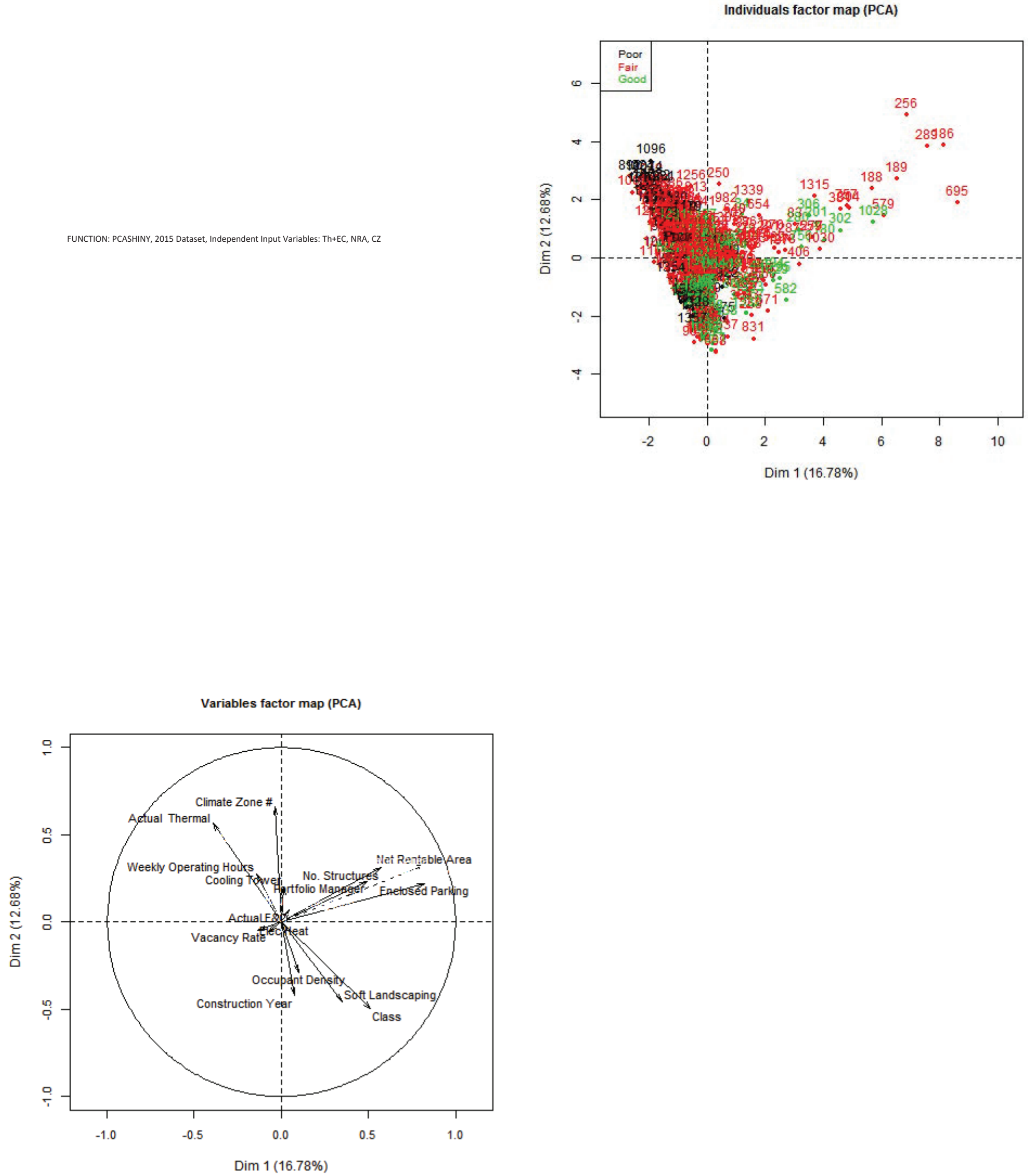
FUNCTION: PCASHINY, 2015 Dataset, Independent Input Variables: Th+EC, NRA, L_L
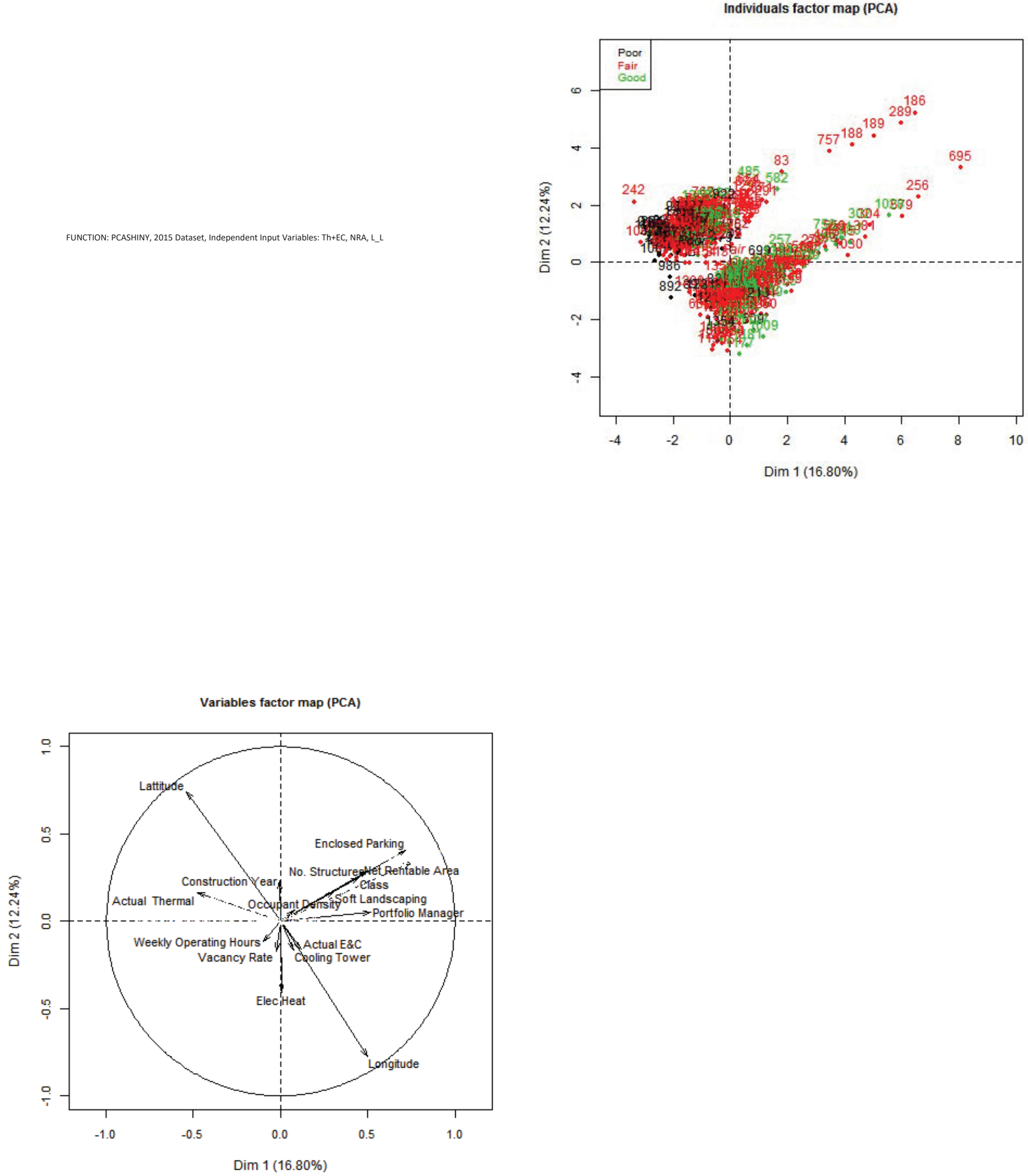
FUNCTION: PCASHINY, 2015 Dataset, Independent Input Variables: Th+EC, NRA+EP, CZ
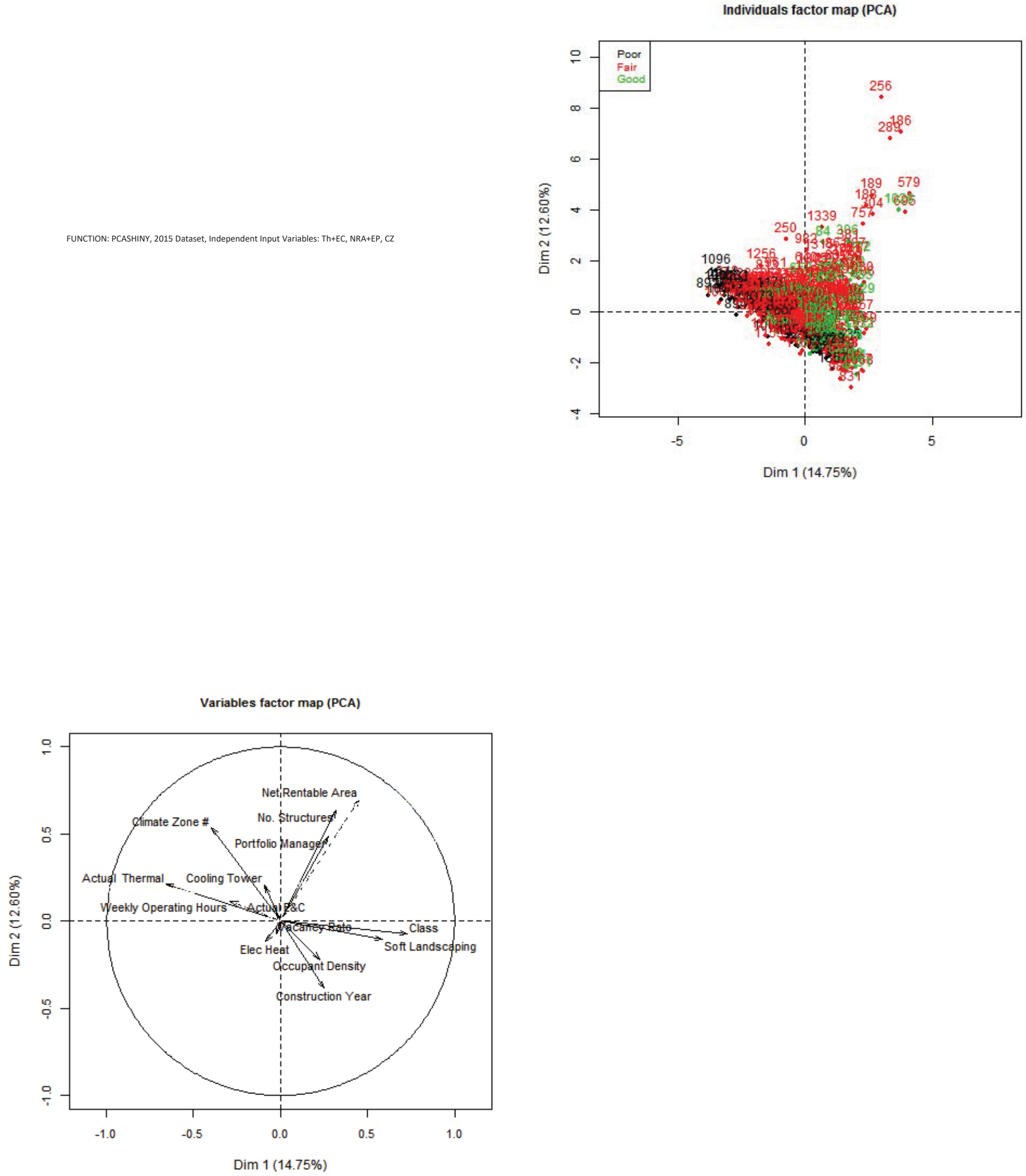

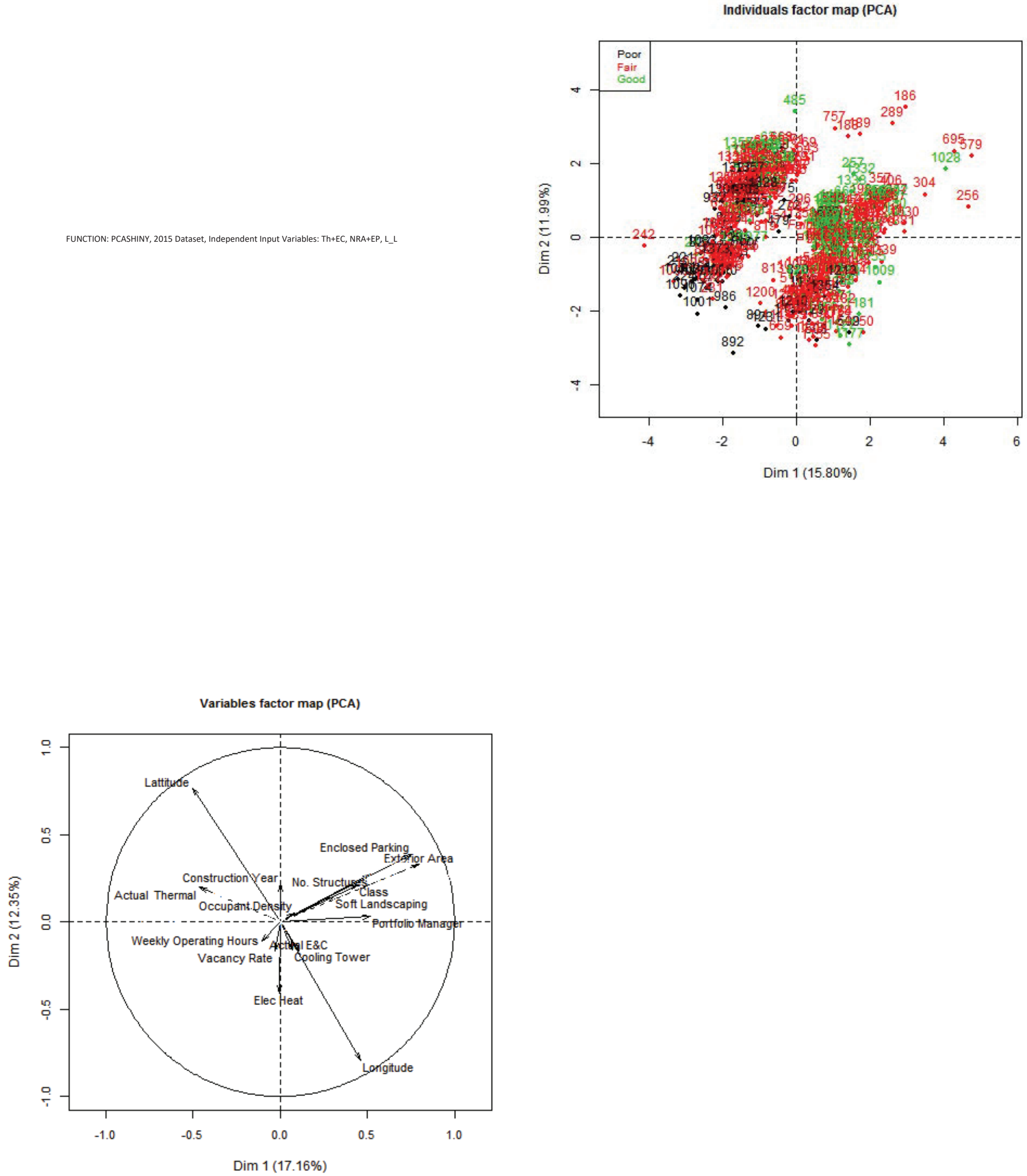